http://dx.doi.org/10.18232/20073496.1280

Artículos

\title{
La fruticultura en el Alto Valle de Río Negro: origen, auge y deterioro, 1930-1965
}

\section{Fruit Growing in the Alto Valle (High Valley) in Rio Negro: Origin, Boom and Bust, 1930-1965}

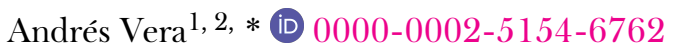

\footnotetext{
${ }^{1}$ Universidad Nacional del Comahue, Neuquén, Argentina.

${ }^{2}$ Universidad Nacional de Río Negro, Viedma, Argentina.

*Correspondencia: andresvera1980@gmail.com
}

Resumen. La producción frutícola ubicada en la región del Alto Valle de la provincia de Río Negro, Argentina, se presenta -actualmente- como un modelo productivo en crisis a partir del deterioro socioeconómico y la desaparición de los pequeños productores característicos de la región. Sin embargo, es preciso mencionar que dicha producción, cuyos inicios se remontan a la década de 1930, pudo experimentar etapas de bonanza y crecimiento, perfilándose en sus primeras décadas como la principal actividad agropecuaria de la economía de la región. El presente artículo pretende explicar los diferentes hechos económicos y políticos que acontecieron durante el trayecto histórico de la producción frutícola, que posibilitaron la configuración de un contexto vulnerable para los pequeños y medianos productores, el cual se evidencia definitivamente en la década posterior a 1955. De esta forma, se sostiene que la construcción histórica de una relación asimétrica entre empresas comercializadoras y productores representó la principal causa de vulnerabilidad.

Palabras clave: desarrollo regional; circuito productivo; monopolio comercial; Patagonia argentina.

CÓMO CITAR: Vera, A. (2022). La fruticultura en el Alto Valle de Río Negro: origen, auge y deterioro, 1930-1965. América Latina en la Historia Económica, 29(2), 1-29. DOI: 10.18232/20073496.1280 
Abstract. The fruit growing activity in the area of Alto Valle (High Valley) in the province of Rio Negro, Argentina, is a productive model that is -at current- going through critical times, as a result of the socioeconomic deterioration and the disappearance of regional small producers. Nevertheless, we should bear in mind that such activity, which began in the 1930's, went through times of growth and prosperity, building itself as the main agricultural activity of the region's economy during the first decades. The purpose of the current article is to explain different economic and political events occurred during the history of fruit growing, which contributed to create a vulnerable scenario for small and mid-sized producers, and which became evident during the decade after 1955. In this sense, it is argued that the main reason for this vulnerability is the historical construction of an asymmetrical relationship between trading companies and producers.

Key words: regional development; productive circuit; commercial monopoly; Argentine Patagonia.

JEL: N56; N96.

Recibido: 25 de noviembre de 2020.

Aceptado: 10 de diciembre de 2020.

Publicado: 28 de febrero de 2022.

\section{INTRODUCGIÓN}

La configuración histórica de la provincia de Río Negro, como parte de la Patagonia Argentina, desde su faz socioproductiva puede diferenciarse en regiones de características particulares, las cuales se perfilaron históricamente -desde su dependencia del poder ejecutivo central hasta su provincialización- en función de sus características geográficas que posibilitaron el asentamiento de la población y el desarrollo de diferentes producciones. En este sentido, las principales regiones pueden clasificarse en Andina, de los Valles (Alto Valle y Valle Medio), Meseta y Atlántica.

En términos generales, luego de promulgada la Ley 1.532 de la Organización de los Territorios Nacionales, bajo la presidencia de Julio Argentino Roca, en la región de los Valles se destacaron actividades relacionadas con la producción de heno de alfalfa desde inicios del año 1900 hasta 1930, y posteriormente con la producción de fruta de pepita (manzanas y peras), ambas aprovechando el potencial productivo que brindan las zonas irrigadas que bordean al río Negro; posteriormente, las actividades hidrocarburíferas se evidencian como principales en todo el territorio. En la región Andina, ubicada en la franja occidental de la provincia, la cual abarca la precordillera y cordillera de los Andes, se afincaron actividades productivas ganaderas relacionadas con la cría de animales vacunos y ovinos; posteriormente las actividades turísticas, comerciales y de desarrollo tecnológico toman relevancia en el entramado económico, destacándose la ciudad de San Carlos de Bariloche como centro urbano y turístico preponderante. En la región Meseta, que ocupa toda el área comprendida entre la cordillera y el mar, la actividad representativa se relaciona históricamente con la producción de lana de oveja y cabra, las cuales eran explotadas, en mayor proporción, por grandes estancias y, en menor volumen, por productores de rasgos precapitalistas (Bandieri, 2005). Por su parte, en la región Atlántica (Valle Inferior), ubicada sobre la costa atlántica y extendida longitudinalmente al este de la Patagonia, la ciudad de Viedma se constituye, según Tagliani (2009), en centro de servicios de la actividad ganadera, lo que se suma a su designación como ciudad, sede de la gobernación de la Patagonia (1878-1884) y posteriormente capital de la gobernación de Río Negro. 
En el plano político, los territorios nacionales se vinculaban estrechamente al poder central con una autonomía restringida en sus funciones y en asignaciones presupuestarias. Por otro lado, los derechos políticos de los habitantes de estas regiones se encontraban restringidos (Ruffini, 2005). Esta configuración territorial y política promovía un ambiente de dependencia absoluta a las decisiones del Estado nacional en cuanto a política económica. Si bien el esquema de territorios nacionales se consideraba como transitorio en la planificación nacional, la ampliación de derechos políticos de los territoriales fue dilatándose a lo largo de décadas, siendo una cuenta pendiente y repercutiendo de manera negativa en la planificación -entre otras cuestiones- de la economía regional.

Determinar las causas históricas que explican el deterioro económico y social de los pequeños y medianos productores frutícolas afinados en el Alto Valle de la provincia de Río Negro, Patagonia Argentina, se plantea como un cuestionamiento al cual este artículo busca dar respuesta. En este sentido, se establece como hipótesis que la integración asimétrica histórica de los productores primarios con las empresas líderes de la producción posibilitaron configurar un escenario de desigualdad, esto en cuanto a las posibilidades de apropiación del excedente económico generado en la actividad frutícola. De acuerdo con lo dicho, diversos autores tales como Milton Santos (1975), García y Rofman (2013) y Rofman (1999) permiten dimensionar algunos de los elementos o factores clave que inciden en determinar las formas de interrelación de los agentes económicos y sociales en un proceso productivo, entre ellas se destacan la oscilación de cantidades ofrecidas, la estacionalidad, el poder de negociación y la capacidad de almacenamiento, entre otras. De este modo, se establece como punto de partida el análisis de la conformación inicial de la fruticultura en 1930, con el objetivo de determinar los principales elementos del circuito productivo en relación con el contexto económico nacional y regional en cuestión. En este artículo se analizan más de tres décadas de desarrollo del circuito frutícola valletano, con un corte final hacia el año 1965. Para tal fin, se procedió al estudio de diferentes eventos de relevancia que afectaron a la región en términos geográficos, económicos y sociales, los cuales permitieron reproducir ciertas normalizaciones a lo largo del periodo analizado que, a la luz de los hechos, estructuraron un marco de vulnerabilidad para los productores primarios afincados en la región. A su vez, se detallan diferentes hechos relacionados con las iniciativas públicas y privadas que dinamizaron el desarrollo del circuito productivo.

Como estrategia general para determinar los principales factores que posibilitaron el deterioro de los rendimientos económicos de los productores primarios, el presente artículo adoptó el método comparativo entre diferentes etapas, las cuales fueron segmentadas en función de hechos significativos de la historia económica nacional, tomando como antecedente el periodo entre los años 1930 y 1943, donde la producción frutícola inicia un sendero de crecimiento. La etapa posterior, es decir, entre 1944 y 1954, permite dimensionar, con base en la consolidación del modelo de industrialización por sustitución de importaciones, un cambio en el régimen de acumulación imperante hasta ese momento (Neffa, 1998), atravesado por una etapa de nacionalizaciones durante el gobierno de Juan Domingo Perón a partir del año 1946, las cuales impactaron de manera significativa en la región analizada. Finalmente, el periodo 1955-1965 se presenta como un quiebre de tendencia en la política económica aplicada debido al golpe de Estado contra el gobierno peronista, permitiendo identificar un periodo de liberalización de la economía nacional y de provincialización del territorio rionegrino. En este contexto se observa un deterioro en las condiciones económicas de los pequeños productores afincados en el Alto Valle. En el marco de la estrategia adoptada, se buscó relacionar los distintos acontecimientos políticos, económicos y sociales de mo- 
do preciso, con base en la relevancia de los hechos visualizados, y procurando detectar vínculos explicativos de la dinámica social específica que se desarrolló durante las etapas estudiadas. Luego, se procedió a la categorización de las políticas económicas y sociales con el objetivo de visualizar aspectos coherentes y contradictorios en un recorrido temporal de importancia trascendente en la historia de la fruticultura valletana.

\section{ANTECEDENTES REgiOnALES}

Alto Valle, inicios de la fruticultura

La compañía inglesa Ferrocarril Sud, fundada en 1862 como Buenos Aires Great Southern Railway, había consolidado en 1884 una vía ferroviaria desde Buenos Aires hasta Bahía Blanca. En una coyuntura atravesada por el conflicto armado con Chile, en disputa por el canal de Beagle, pudo darse lugar la apertura estratégica de la compañía inglesa hacia otras regiones. La necesidad de la fluidez de tránsito hacia el Alto Valle por parte del gobierno argentino fue motor fundamental para la negociación con Ferrocarril Sud (Vera y Ferreyra, 2015). La empresa aceptó construir la línea férrea a cambio de una serie de beneficios como exenciones impositivas nacionales, provinciales y municipales por 50 años para todas las propiedades de la empresa, exención de derechos de importación para todos los materiales a introducir por la empresa en el país para construir y explotar su red entera, y autorización para construir muelles para uso exclusivo de la empresa en el puerto de Bahía Blanca (Rögind, 1937).

A partir de este encadenamiento de factores, la planificación estratégica de los capitales ingleses esbozó un escenario de posibles rentabilidades. En sólo tres años la empresa Ferrocarril Sud construyó un ramal ferroviario de aproximadamente $670 \mathrm{~km}$, que se extendía desde Bahía Blanca hasta Cipolletti (confluencia de los ríos Neuquén y Limay), pasando por las estaciones de Río Colorado y Darwin. En el año 1899, con la presencia del presidente Julio Argentino Roca, dicho ramal quedó inaugurado, lo que constituyó un hecho de importancia trascendental en la historia del Alto Valle de Río Negro. Es necesario subrayar que este suceso estuvo acompañado por otro hecho de resonancia histórica: la destrucción del fuerte General Roca provocado por la creciente del río Negro. Ya en 1910, y en medio de las obras de irrigación necesarias para enfrentar la problemática inundación, que consistieron en la construcción (por parte de Ferrocarriles Sud) del dique sobre el río Negro aguas arriba, se inauguró un corto ramal de $30 \mathrm{~km}$ hasta Contraalmirante Cordero, destinado al traslado de personal y de todos los materiales para dicha represa. En 1914, el ferrocarril se hizo presente en Zapala, donde concluyó la extensión de la mitad del proyecto que pretendía unir Neuquén con Chile.

La presencia del tren significó un cambio radical en las comunicaciones, en el traslado de pasajeros y, principalmente, en el transporte de cargas, todo esto trascendió positivamente en la vida comercial del Alto Valle rionegrino. La empresa Ferrocarril Sud desempeñó un papel fundamental en las obras de irrigación en el territorio (año 1911), financiando $50 \%$ del inicio de las obras de construcción del dique sobre el río Neuquén, de los canales de riego y los desagües que conformarían el Sistema Mayor de Riego del Alto Valle del Río Negro y Neuquén; por otro lado, en 1918 promovió la construcción de la Estación Agronómica de Cinco Saltos, destinada a la experimentación y transmisión de conocimiento a los agricultores, con el objetivo de incrementar la cantidad de productos para la exportación (Álvarez, 2012). Así, el capital inglés mostraba un decisivo interés en dirigir el proceso de reconversión productiva hacia la fruticultura y adjudicaba en 
ella un importante papel a la explotación familiar. Para 1930, en la preocupación por responder a la demanda internacional con la calidad y cantidad de frutas requeridas, la empresa ferroviaria colocaría la Estación Agronómica bajo la dependencia de una empresa comercializadora que crearía para ese fin, bajo la razón social Argentine Fruit Distributors (en adelante AFD).

La crisis de 1929 y su afección a la economía mundial, caracterizada por una pronunciada deflación, se manifestó en un entramado de restricciones monetarias y financieras, caída de precios y salarios y caída de las actividades económicas (Rapoport, 2007). El impacto en el sector industrial mundial provocó una caída acentuada de la demanda y precios internacionales de materias primas, impactando en las economías de países agroexportadores, entre los cuales se encontraba Argentina. La crisis del sector externo nacional derrumbó las exportaciones $36 \%$ entre 1929 y 1930 , marcando un déficit en la balanza comercial; a su vez, la relación desfavorable entre los precios agropecuarios en relación con los precios industriales promovieron un deterioro de los términos de intercambio, afectando el equilibrio de la balanza de pagos y presionando sobre la cotización de la moneda. Por su parte, el Estado nacional estructuró una serie de medidas de política económica de carácter intervencionista entre las cuales se destacaron el control de cambios, la creación del Banco Central y regulaciones en los mercados de bienes con el propósito de dinamizar las producciones locales. De igual manera, se comenzaron a estructurar y planificar diferentes acciones que se derramaron paulatinamente hacia la producción, conservación y comercialización de la fruta, tanto en el Alto Valle de Río Negro y Neuquén como en la provincia de Mendoza. La política económica nacional intentó, en este marco, establecer novedosas acciones políticas para regularizar el curso de la producción frutícola, incentivando el desarrollo del mercado interno en respuesta al deterioro de los mercados externos.

En dicho contexto debe considerarse el interés que despertó un potencial desarrollo racional y eficiente de la fruticultura, desarrollando y satisfaciendo la demanda interna para orientar luego otras especies de frutas y otras zonas productoras hacia la comercialización externa (Ospital, 2012). Desde el Ministerio de Agricultura, se establecieron los primeros parámetros para regular una explotación productiva que enfrentaba por primera vez turbulencias económicas. La acción de dicha institución se basó tanto en la creación de estructuras gubernamentales como en el apoyo y fomento de instrumentos de comunicación hacia los productores. Sin embargo, la acción estatal no establecía ninguna regulación sobre los agentes intervinientes en el circuito, soslayando tanto el grado de concentración del mercado en las etapas de producción, empaque y comercialización, como la regionalización y apropiación de excedentes generados por el circuito. Así, la actividad frutícola del Alto Valle de Río Negro y Neuquén se desarrolló a partir de la acción protagónica del capital inglés, traccionada por las compañías AFD y Ferrocarril Sud (en cuanto al transporte y comercialización de la fruta fresca). Por su parte, el Estado propició la intervención directa de estas firmas de origen extranjero, ya que permitió el control tarifario de la producción sin la necesidad de intervenir directamente en la etapa productiva.

A estos efectos, el capital británico aseguró márgenes de ganancia, lo que estimuló la aparición de pequeñas explotaciones, financiando parcialmente su organización productiva y brindando la capacitación necesaria para la adaptación del producto final a las preferencias de los consumidores extranjeros (Bandieri, 2005). De esta forma, las acciones de las firmas británicas optaron por el control del empaque, el transporte y la comercialización, evitando la integración vertical de la etapa productiva, lo cual trajo como resultado una fragmentación de los productores en pequeñas explotaciones individuales de carácter nacional, frente a un monopolio consolidado de origen extranjero. En este punto es importante destacar que dicha fragmentación posibilitó categorizar 
históricamente como unidades productivas a manos de pequeños productores, dando lugar a la aparición de un sujeto social característico de la región: el chacarero productor de manzanas y peras, propietario de una porción de tierra bajo riego de siete a diez hectáreas promedio.

Este tamaño característico de pequeña explotación frutícola debe su origen a la compañía Tierras del Sud (subsidiaria de Ferrocarril Sud), la cual inició un proceso de compraventa de chacras en fracciones de dos a 50 hectáreas, con facilidades para los adquirentes. Estas unidades productivas estuvieron fuertemente orientadas, en primera instancia, al cultivo de alfalfa y poco después hacia una producción decididamente frutícola, en pequeñas parcelas de carácter familiar (Bandieri y Blanco, 1998). Dichos eventos promovieron formas de subdivisión de la tierra, formando charcas de entre diez y doce hectáreas promedio, que a medida que ingresaban en el Sistema de Riego Mayor de Alto Valle se revalorizaban en forma considerable (Vera y Ferreyra, 2015). Cabe destacar que la empresa Tierras del Sud fue uno de los capitales privados con mayor participación en la colonización del riego en el Alto Valle, actuando sobre la región a partir de octubre de 1908. $\mathrm{Su}$ objeto era la compraventa de tierras, la fabricación de hornos de ladrillo y la gestión de las concesiones de vías férreas, entre otras actividades.

La población creció 2.4 veces entre las décadas de 1930 y 1940, pasando de 12500 a 42600 habitantes, acentuándose en la década de 1940 hasta 1950. La zona del Sistema Mayor de Riego fue claramente la elección predominante por parte de los colonos.

En todo proceso de acumulación existe un dinamismo en las rentas que se producen, en cuanto a la cantidad o volumen de excedentes como también en los diversos agentes que se apropian de estas, y en este sentido las acciones públicas y privadas - por parte del Estado nacional y el capital inglés- generaron condiciones particulares en la región, como una planificación orientada (a partir de la conquista socioeconómica del desierto) bajo dos pilares fundamentales: la ley 5.559, de Fomento de los Territorios Nacionales, y la ley 6.546, de Irrigación (Martínez de Gorla, 1994). En este sentido, la Ley de Fomento de los Territorios Nacionales promovía una estrategia de integración ferroviaria de las áreas potencialmente productivas en los valles cordilleranos y la meseta, combinando el uso del tren con las vías navegables y los puertos marítimos.

\section{Argentine Fruit Distributors (AFD). Producción y comercialización}

Vera y Ferreyra (2015) sostienen que el empaque y la comercialización de la fruta se hacían, antes de 1930, en forma precaria, lo que ocasionaba pérdidas en cuanto al volumen y calidad de la fruta, sea por manejos defectuosos, sea por empaques incorrectos. Los galpones de empaque operaban deficientemente y debían mejorarse con el fin de posibilitar el crecimiento del circuito productivo y, consecuentemente, de abrir novedosos mercados en Europa. Para 1929, la AFD pudo instalar plantas de empaque en las propias playas ferroviarias de Cinco Saltos, Cipolletti, Allen y J. J. Gómez, y unos años después hizo lo propio en Villa Regina. Vera y Ferreyra (2015) afirman que la empresa impuso el uso de cajones cosecheros estándar, en los cuales la fruta se trasladaba por camión o por carro, recién cosechada, desde la chacra al galpón. Allí se clasificaba la fruta en forma mecánica por tamaño y a mano, por calidad, teniendo en cuenta también la presentación. Durante los años de preguerra, la empresa llegó a comercializar cerca de 80 \% de la producción total de la fruta y a empacar un porcentaje aún mayor.

En las primeras tres décadas de la fruticultura valletana, las labores primarias se realizaron de manera similar, casi sin modificaciones en cuanto a técnicas de siembra, cultivo, cuidado y cosecha, aportados en el inicio de la actividad frutícola por la Estación Agronómica Experimental de Cinco 
Saltos (creada en 1918 por capitales ingleses), cuyo objetivo primordial era el de incrementar la producción en el Valle para intensificar el transporte. En esta organización, trabajaron importantes genetistas y fitopatólogos, como el ingeniero Enrique Amos y Jaime McDonald. Dicha estación importaba y reproducía, en sus viveros, variedades elegidas de frutales injertados para su venta a plazos, con precios de fomento a los fruticultores y sugerencias de los técnicos en publicaciones gratuitas para el productor (Bandieri y Blanco, 1998).

Por otro lado, las innovaciones tecnológicas durante estos años se relacionaron en gran medida con la conservación, transporte y comercialización de la fruta fresca y no a las mejoras en labores primarias. En promedio, las pequeñas unidades productivas destinaban seis hectáreas a la producción de manzanas y peras, con un rendimiento promedio de 30 toneladas en total. Vapñarsky (1983) sostiene que el ciclo agroindustrial de la fruticultura se inicia a partir de 1967, donde se consolidan la capacidad industrial frigorífica, el reemplazo definitivo del transporte ferroviario por el terrestre en camiones y el desplazamiento de las vías de exportación desde el puerto de Buenos Aires hacia otros puertos. En este sentido, a partir de ese año pueden observarse mejoras en las técnicas de laboreo primarias, tales como la introducción de portainjertos enanizantes para obtener plantaciones bajas llamadas en espaldera. Por lo tanto, y a la luz de los aportes bibliográficos referenciados, resulta comparable la estructura de rendimiento productivo y económico en el eslabón primario en la etapa analizada (véase gráfica 1).

\section{GRÁFICA 1. PRODUCGIÓN DE PERAS Y MANZANAS EN TONELADAS. REGIÓN VALLETANA, 1933-1943}

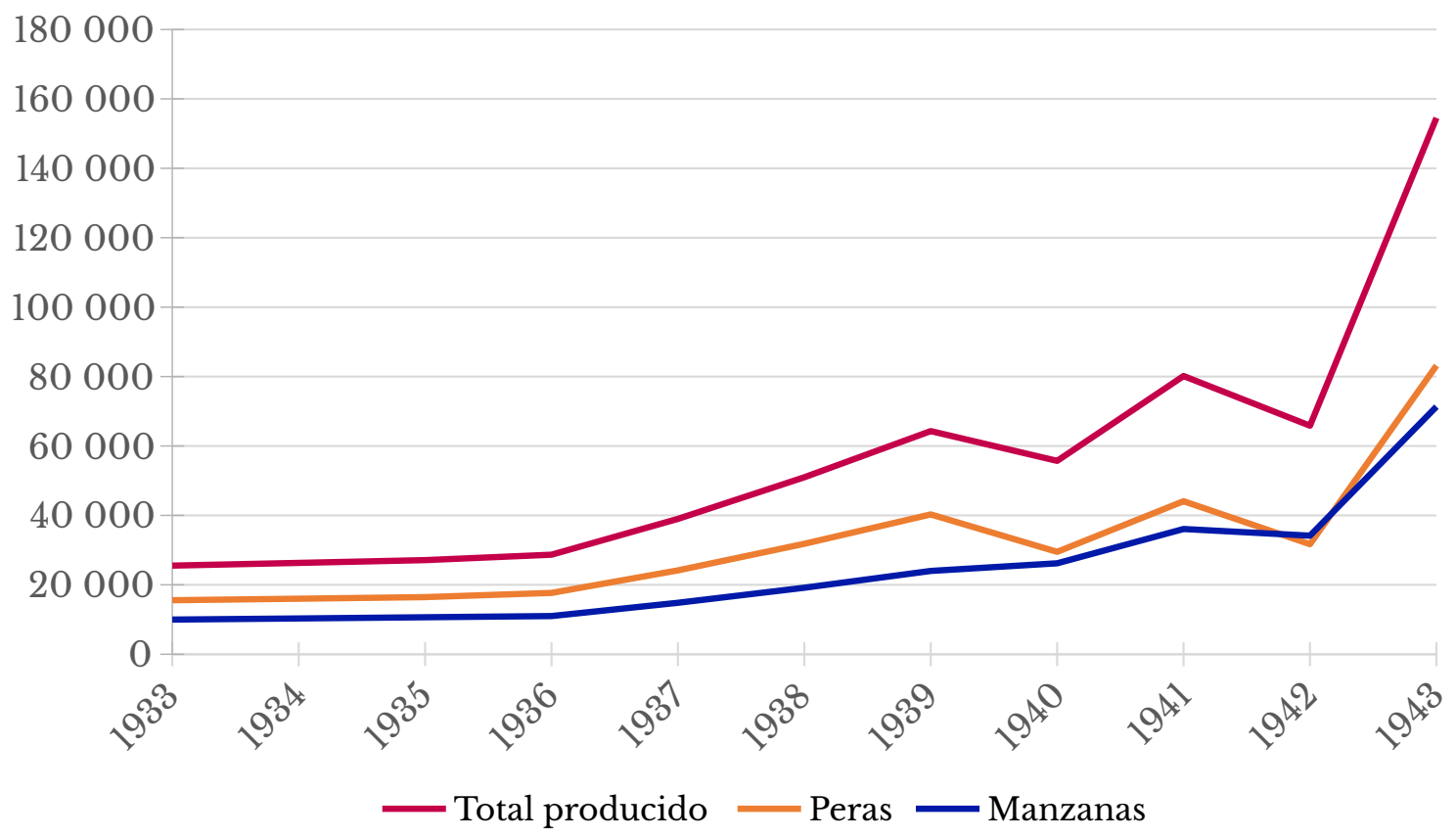

Fuente: elaboración propia con base en Dehais (2000). 
El crecimiento de 1942 a 1943 es notable, lo cual demuestra que el objetivo del capital inglés comenzaba a concretarse de manera acelerada. La coyuntura de la segunda guerra mundial generaría una caída en la demanda internacional de productos agropecuarios con impacto en las exportaciones de fruta nacional. Todo ello atenúa el ritmo de crecimiento de la producción en la región valletana. Es evidente que cuando la expectativa de exportación se volvía adversa, como consecuencia del deterioro del contexto internacional, la producción para el mercado interno se acentuaba, generando - a pesar de ciertas concepciones conservadoras - un marco de mayor estabilidad. Es necesario aclarar que, desde sus inicios y dados los varietales específicos de producción incentivados por el capital inglés, la vocación de los productores primarios orientaba sus objetivos comerciales a los mercados de ultramar. Puede constatarse en profusa bibliografía y diversas estadísticas que las exportaciones fueron creciendo desde la consolidación del circuito productivo, perfilándose como la región productiva principal para abastecer la demanda internacional (véase gráfica 2). Es evidente la alta participación en el total de exportaciones nacionales en 1936, cuando la región valletana representó $74 \%$ del total de manzanas y $72 \%$ del total de peras, y en 1937 , cuando aportó $83 \%$ del total de manzanas y $92 \%$ del total de peras. Por otro lado, se observa una marcada caída de las exportaciones entre 1939 y 1943, aunque sin detrimento de los niveles de producción, que siguieron una pronunciada tendencia positiva.

\section{GRÁFICA 2. EXPORTACIONES NACIONALES DE PERAS Y MANZANAS EN TONELADAS, 1933-1943}

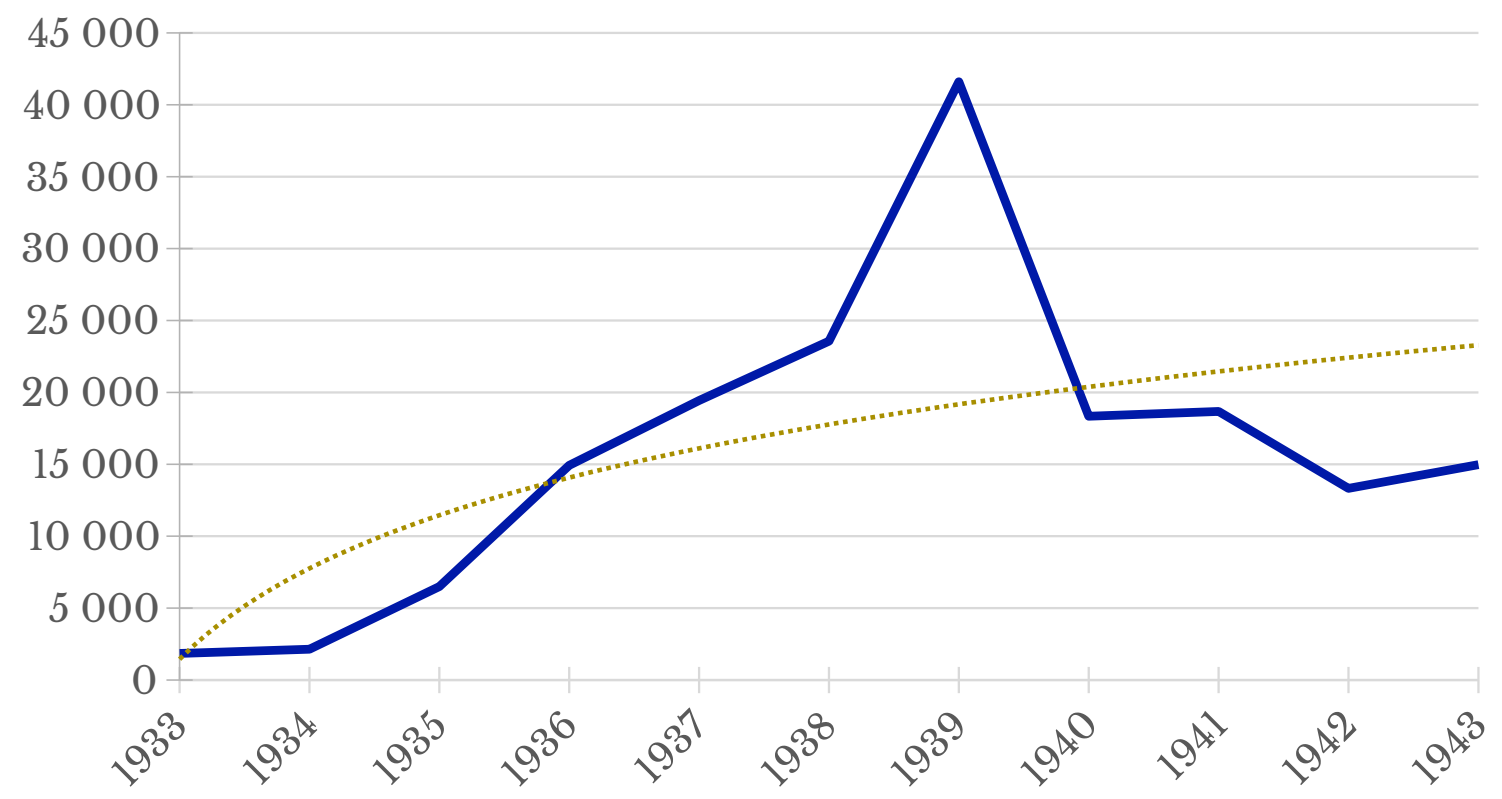

Fuente: elaboración propia con base en Dehais (2000).

Esta situación no se debió a una caída en el precio internacional de las frutas de pepita, sino a la baja demanda en los años de guerra. Los precios promedio internacionales de ambas especies (peras y manzanas) en el mercado de Nueva York se mantuvieron estables desde 1933 hasta 1940, y recién comienzan a incrementarse en los años siguientes. Es importante destacar que a pesar del 
aumento de los precios internacionales en el periodo 1941-1943, las exportaciones nacionales no recuperaron los volúmenes observados en 1939, cercanos a las 40000 toneladas, por el contrario, tocaron volúmenes similares a los 1936, cercanos a las 15000 toneladas.

Otro aspecto para destacar fue el mecanismo de comercialización, a través del cual la AFD se aseguró una renta monopólica. La empresa no compraba la fruta, sino que la tomaba en consignación sin asegurarle al productor precio alguno. La retribución sólo llegaba una vez que el producto completaba su ciclo en el mercado de destino. Del precio final obtenido se descontaba una comisión y se le pagaba la diferencia al productor. Para ilustrar la estructura de negocio que la AFD promovía en la etapa de producción con la intención de fomentar el cultivo de la fruta de pepita, este artículo toma como referencia a Bandieri y Blanco (1991), quienes -a su vez- sustentan su modelización en el estudio de costo-producción efectuado por el ingeniero agrónomo Fernando Salcedo, es decir, de acuerdo con los precios máximos cotizados en la campaña 1938-1939 (Wetzler, 1941). En el caso particular de los avances correspondientes al aporte de las autoras, y realizando los cálculos correspondientes para la cosecha 1938-1939 (Vera, 2017) (considerando una chacra promedio de siete hectáreas con plantación mixta de perales y manzanos) la tasa de ganancia de los productores ascendió a $27.8 \%$ anual (véase anexo 1). Por otra parte, la tasa interna de retorno -en cinco temporadas anuales- ascendió a $12 \%$ anual y una tasa de rentabilidad neta sobre ventas de $55.5 \%$ anual.

\section{LA FRUTICULTURA EN UN ESCENARIO DE NAGIONALIZACIONES}

El contexto internacional, de reordenamiento geopolítico centrado en la consolidación de Estados Unidos como potencia industrial y militar, permitió un paulatino desacople de la economía nacional en el plano comercial respecto a Gran Bretaña, incentivado - a su vez- por la orientación de la política nacional peronista hacia un proceso de fortalecimiento de la dinámica interna de acumulación, basada en un claro intento de desarrollo nacional. La dinámica de acumulación se volcaba entonces al fortalecimiento del mercado interno: incentivo a las inversiones en diferentes gamas industriales -incluyendo los segmentos agrícolas- y aumento de los salarios nominales por encima de los índices inflacionarios con el objetivo de aumentar la demanda (capacidad de compra de los asalariados), para asegurar a los empresarios industriales tasas de ganancias acordes a sus expectativas.

Este periodo histórico, en el cual el circuito productivo frutícola del Alto Valle comenzó a desarrollarse definitivamente, se caracterizó por la apropiación y gestión de una porción de la renta agraria por parte del Estado, lo cual permitió efectuar transferencias de ingresos desde el sector agropecuario hacia el resto del sistema productivo. Estas iniciativas se vieron reflejadas con claridad durante el Primer Plan Quinquenal (fines de 1946 hasta 1951) durante el gobierno de Juan Domingo Perón, cuya impronta se apoyaba sobre tres pilares principales: $a$ ) industrializar y diversificar la matriz productiva del país, modificando el perfil agroexportador y permitiendo la sustentabilidad de un modelo de desarrollo endógeno (independencia económica); $b$ ) recuperar la capacidad del Estado nacional para organizar y tomar decisiones de política interna y de política externa independientes, latinoamericanista y tercerista (soberanía política), y c) emancipar social, educativa y culturalmente a los trabajadores y a los empresarios nacionales, generando condiciones de vida dignas para todos los habitantes del país (justicia social). Esta particularidad de desarrollo industrial pensado hacia dentro generaría una dinámica de crecimiento de la economía y reconfiguración de la distribución de los excedentes económicos, denominado stop and go, el cual expresó, 
en el devenir de la historia nacional, sucesivos intentos de consolidar un aparato productivo industrial de características intensivas en su forma de acumulación del capital, que cíclicamente se vio enfrentado a una recurrente restricción externa. La política económica adoptada por el gobierno peronista enfrentaba el desafío de encadenar dos modelos de desarrollo diferentes: el referido a la explotación agropecuaria con visibles rasgos de decadencia, por un lado, y un nuevo motor basado en las producciones industriales, por otro. La coyuntura colocaba al país ante una problemática compleja que exigía la estructuración de un nuevo esquema económico (Vera, 2013).

En esta nueva etapa -y sobre todo con la llegada de Perón a la presidencia en 1946-, el peronismo, en contraste con la década anterior, imprimió al Estado una orientación completamente diferente. La estrategia económica fue netamente proteccionista, intervencionista y dirigida al desarrollo de los sectores populares. Para ilustrar esta tendencia, se pueden destacar las iniciativas llevadas a cabo desde la Secretaría de Trabajo y Previsión, como por ejemplo la fijación de salarios mínimos e indemnizaciones por accidente de trabajo, la sanción del Estatuto del Peón Rural de 1944, el sostenido crecimiento del Estado como proveedor de servicios (sobre todo, de servicios públicos como gas, telefonía, energía, etc.), la intervención en entidades financieras (en especial en el Banco Central, que deja de ser mixto en marzo de 1946) y la creación de instituciones para insertar la economía nacional en el comercio exterior (Instituto Argentino de Promoción del Intercambio, en adelante IAPI). Por otro lado, en línea con la estrategia nacional de fortalecer a la industria, el Primer Plan Quinquenal estableció una zonificación funcional y le asignó a la Patagonia la función de fábrica de energía para la industrialización de las regiones centrales del país.

\section{El impacto en la configuración del espacio regional}

En este escenario, la fruticultura del Alto Valle experimentó un fuerte crecimiento en su producción, consolidando mercados internos y externos. La actividad frutícola, por su parte, ejerció un peso importante en el producto bruto geográfico ( $\mathrm{PBG}$ ) del territorio valletano, aportando $16.38 \%$ al total del PBG regional en 1954, que representa $54.1 \%$ en el total de la actividad agrícola, principal dinamizadora de la economía del territorio de Río Negro (República de Argentina, Consejo Federal de Inversiones, 1963). Dos hechos fundamentales distinguieron la política peronista en el periodo analizado y en la región del Alto Valle en particular. Por un lado, la nacionalización de los ferrocarriles, hecho que generó un reacomodamiento en cuanto a las tarifas como principal instrumento de negociación vinculado con los capitales ingleses, y por otro lado, la nacionalización de la AFD; estos sucesos orientaron un nuevo contexto donde el Estado pasó a convertirse en un agente económico central, generando e incentivando un cambio rotundo en el origen del capital de los agentes protagónicos anteriores.

Así, la compañía Ferrocarril Sud pasa entonces a manos del Estado nacional bajo la denominación Ferrocarril Nacional General Roca y, por lo tanto, todas sus empresas subsidiarias pasaron a ser parte de la administración central del Estado, repartidas en sus diversas entidades estatales. Por su parte, la AFD pasó a llamarse Distribuidora Argentina de Frutas y dejó de ser el agente central del circuito productivo frutícola, perdió eficiencia y en diferentes momentos cerró sus plantas de empaque (CEPAL, 1991). De hecho, la empresa deja de comercializar frutas en 1949, lo que en cierta medida representa un retroceso de la actividad en cuanto a los sistemas de embalaje, que se precarizaron. 
GUADRO 1. POBLACIÓN DE AGLOMERACIONES DEL ALTO VALLE DE RÍO NEGRO Y NEUQUÉN, 1930-1960

\begin{tabular}{lrrrr}
\hline Aglomeración & 1930 & 1940 & 1950 & 1960 \\
\hline Neuquén & 3000 & 4450 & 12850 & 24600 \\
General Roca & 4100 & 5100 & 9800 & 18250 \\
Cipolletti & 1800 & 2400 & 5650 & 13600 \\
Villa Regina & 500 & 1900 & 3050 & 8250 \\
Cinco Saltos & 300 & 800 & 2400 & 7900 \\
Allen & 1600 & 2100 & 3650 & 6500 \\
Centenario-Ing. Huergo & 500 & 1550 & 2800 & 4200 \\
Resto de aglomeraciones & 700 & 1200 & 2400 & 5950 \\
Total & 12500 & 19500 & 42600 & 89250 \\
\hline
\end{tabular}

Para ilustrar el dinamismo que la planificación inglesa imprimía a la actividad, podemos citar que en Cipolletti las plantas de empaque aumentaron de siete en 1943 a 33 en 1947, y el número de máquinas clasificadoras pasó de trece a 26 entre esos mismos años (CEPAL, 1991). Estos hechos fundamentales impactaron, sin dudas, en la cadena de valor frutícola, al generar un reacomodo de agentes ante la salida del principal agente comercializador y la recomposición del transporte, vital en la determinación de las tarifas del único flete integrado a la actividad.

Retomando el análisis, es interesante observar el crecimiento acumulado de la población en las tres décadas siguientes a 1930. La población aumentó 6.14 veces en la sumatoria de las diferentes aglomeraciones hasta 1960; si tomamos la última década, el crecimiento evidenciado fue de 1.09 veces, lo cual representa un ritmo elevado y sostenido (véase cuadro 1). Por otro lado, si cotejamos el crecimiento a niveles productivos de la actividad frutícola en el acumulado de todo el periodo, podemos evidenciar un crecimiento de 16.13 veces, ${ }^{1}$ siendo la actividad predominante y principal motor de la economía provincial. Aquí cabe realizar un contraste entre la primera etapa de producción y comercialización, bajo predominio del capital inglés, y esta segunda etapa, con las respectivas nacionalizaciones que se operaron al interior del circuito frutícola.

$\mathrm{Si}$ bien las nacionalizaciones del principal transporte y comercializadora-empacadora representaron un cambio sustancial en cuanto al origen del capital, los nuevos agentes intervinientes en el circuito frutícola valletano no estuvieron afincados en la región. Desde luego, el transporte respondía a la esfera de la administración nacional de los recursos, y en el caso de la comercialización, es de vital importancia destacar que la AFD pasó a manos de un conjunto de empresas nacionales que reprodujeron relaciones similares a las de la compañía inglesa. Existe abundante bibliografía que muestra esta situación. Jong (2010) y Vapñarsky (1983) concuerdan en que a partir del bienio 1947-1948 algunas cooperativas -y sobre todo ciertas empresas- de Buenos Aires y de Bahía Blanca abarcaron el mismo espectro de funciones de la AFD, demostrando un alto grado de concentración en el eslabón comercial, conjuntamente a un gran poder de negociación para la compra de la fruta fresca. Bandieri (2005) asegura que al final de la década de 1940 diferentes empresas de comercialización afincadas preferentemente en Buenos Aires y vinculadas con los grandes centros de distribución mayorista del país - en especial, el mercado del abasto- se expandieron en forma

${ }^{1}$ Los datos de producción para el año 1930 fueron de 22.530 toneladas, llegando en 1960 a 386000 toneladas. 
notable. La integración vertical por parte de empresas mayoritariamente extrarregionales supone una configuración espacial y territorial particular, en virtud de la planificación estratégica de los agentes intervinientes en el circuito.

\section{Producción, comercialización y concentración}

En cuanto a la configuración productiva, se puede observar un crecimiento leve respecto a la evolución de la superficie cultivada bajo riego y su correspondiente planificación. En cambio, sí es notable el incremento en el número de lotes. El proceso de subdivisión de la tierra quedó bien definido entre 1929 y 1945, lo que resultó en un promedio por lote de 16.2 hectáreas. Al respecto, Kloster (1988) afirma que hacia 1950 el promedio por lote era cercano a las diez hectáreas (cabe destacar que en la etapa anteriormente analizada el promedio se ubicaba en las 16 hectáreas), y $75 \%$ del total de lotes eran inferiores a las 20 hectáreas, predominando -respecto al sistema de tenencia- el régimen de propiedad. A su vez, la inversión en capacidad de frío generó una sustancial modificación en el circuito productivo frutícola, el cual -al consolidarse la inversión en capacidad frigorífica- pasó a considerarse en la literatura específica como la etapa agroindustrial de la fruta (a partir del año 1966).

El impacto de estas medidas por parte del Estado respecto a los niveles de producción presenta una caída pronunciada en el bienio 1947-1948 (véase gráfica 3). La diferenciación de la especie producida (manzanas y peras) y la coincidencia en la caída de ambas frutas nos permiten deducir que la problemática endógena del circuito prevaleció por sobre otras causas posibles de carácter nacional. Es importante destacar la caída de $52 \%$ en la producción en el bienio 1947-1948, de la cual surge la primera evidencia de la debilidad del circuito ante -por lo menos- dos características fundamentales. La primera se vincula con la vulnerabilidad en cuanto a la comercialización de los niveles de producción ante la salida del agente principal del circuito -como lo era hasta entonces la AFD-; el reacomodamiento de agentes ocurrido en ese año comenzaría una fase expansiva de la actividad, denominada, según Jong, Tiscornia y Bandieri (1994) "etapa del predominio del capital oligopsónico nacional”, tesis a la que este trabajo se adhiere. El retiro de la empresa de capitales ingleses de la actividad, como agente central y coordinador, representó un impacto de gran magnitud.

A escala nacional, la creación del IAPI suponía una cooptación de las estructuras del comercio exterior por parte del Estado, lo cual le aseguraba el control de las grandes empresas y de los precios para reducir el margen de acción monopólica y oligopólica de los agentes competidores, administrando al mismo tiempo los pedidos de divisas y aplicando regulaciones extraarancelarias. Esta configuración macro supuso para la fruticultura una situación particular, puesto que la producción de frutas frescas de pepita era considerada cultivo especial y, por lo tanto, su comercialización quedaba fuera de la órbita del IAPI, posibilitando que este grupo monopsónico de empresas estableciera el control del eslabón comercial y construyera, al mismo tiempo, una regularidad hacia el interior del circuito que perduraría en el futuro. Basta mencionar al respecto que, en 1968, sólo 16 empresas exportaron cerca de 50 \% del total (Rotary Club, 1974). Es evidente que el cambio de la política nacional se derramó también hacia el circuito frutícola. Al quitar del juego a su principal agente, el capital inglés -integrador de toda la cadena de valor-, se generó una reconfiguración de actores intervinientes que produjo inestabilidad en la producción y comercialización de stocks. 
GRÁFICA 3. PRODUCGIÓN DE MANZANAS Y PERAS EN LA REGIÓN ALTO VALLE. AÑOS 1944-1954

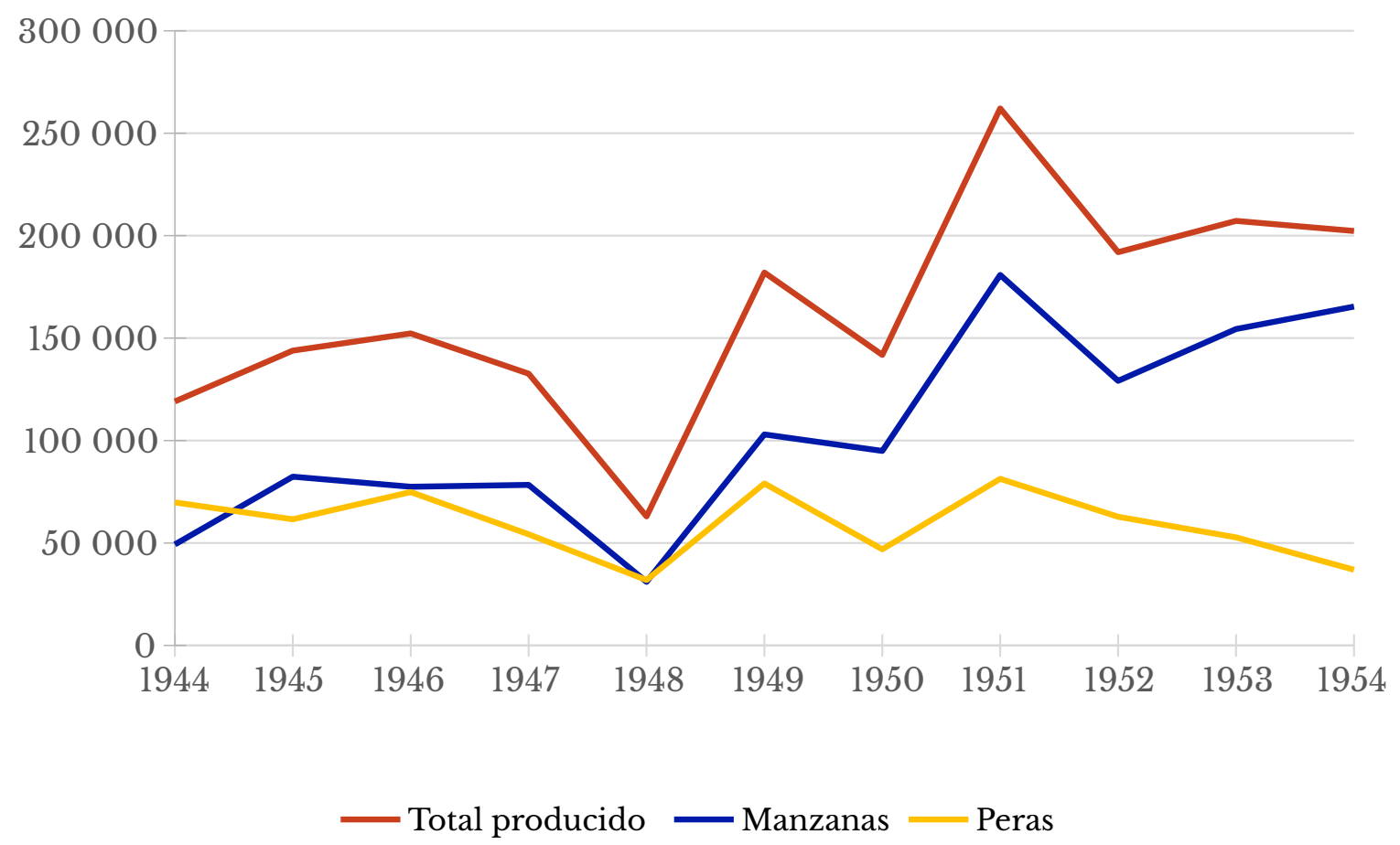

Fuente: elaboración propia con base en Dehais (2000).

En términos relativos, los datos demuestran que -con excepción del año $1948,{ }^{2}$ en que la producción sufrió un estancamiento producto del reacomodamiento de los agentes intervinientes y de la reconfiguración de los mercados externos- el peso del Alto Valle sobre el total nacional fue incrementándose, partiendo de casi $49 \%$ en el año de 1944 a $66 \%$ en 1954.

El circuito mostraba tendencias de consolidación comercial hacia los mercados de ultramar, lo que capitalizó la bonanza de los buenos precios internacionales, cuya cotización se mantuvo estable en el mercado de Nueva York durante todo el periodo. ${ }^{3}$ Una vez finalizada la segunda guerra mundial, las exportaciones comenzaron un crecimiento sostenido que se extendería hacia las siguientes décadas (véase gráfica 4).

El peso de la producción regional se consolidaba con el correr de los años, al acentuar su participación sobre otras regiones, tales como Buenos Aires y Mendoza. La creciente producción regional -y consecuentemente nacional- presentaba dificultades relacionadas con la demanda de fruta fresca, la cual requería acciones conjuntas del Estado y las empresas privadas que lideraban la producción. El desarrollo económico de la región suponía estrategias para incentivar tanto el mercado externo como el interno, con sus respectivas particularidades. Si bien el mercado brasi-

${ }^{2}$ La producción nacional muestra una caída de 68000 toneladas de producción, afectando en 17560 toneladas a las exportaciones y en 50440 toneladas al mercado interno.

${ }^{3}$ El precio de la pera promedio fue de 4.6 dólares. El precio promedio de los principales varietales de manzana fue de 3.8 dólares (US Department of Agriculture, s. f.). 


\section{GRÁFICA 4. EXPORTACIONES NACIONALES DE PERAS Y MANZANAS (EN TONELADAS), 1944-1954}

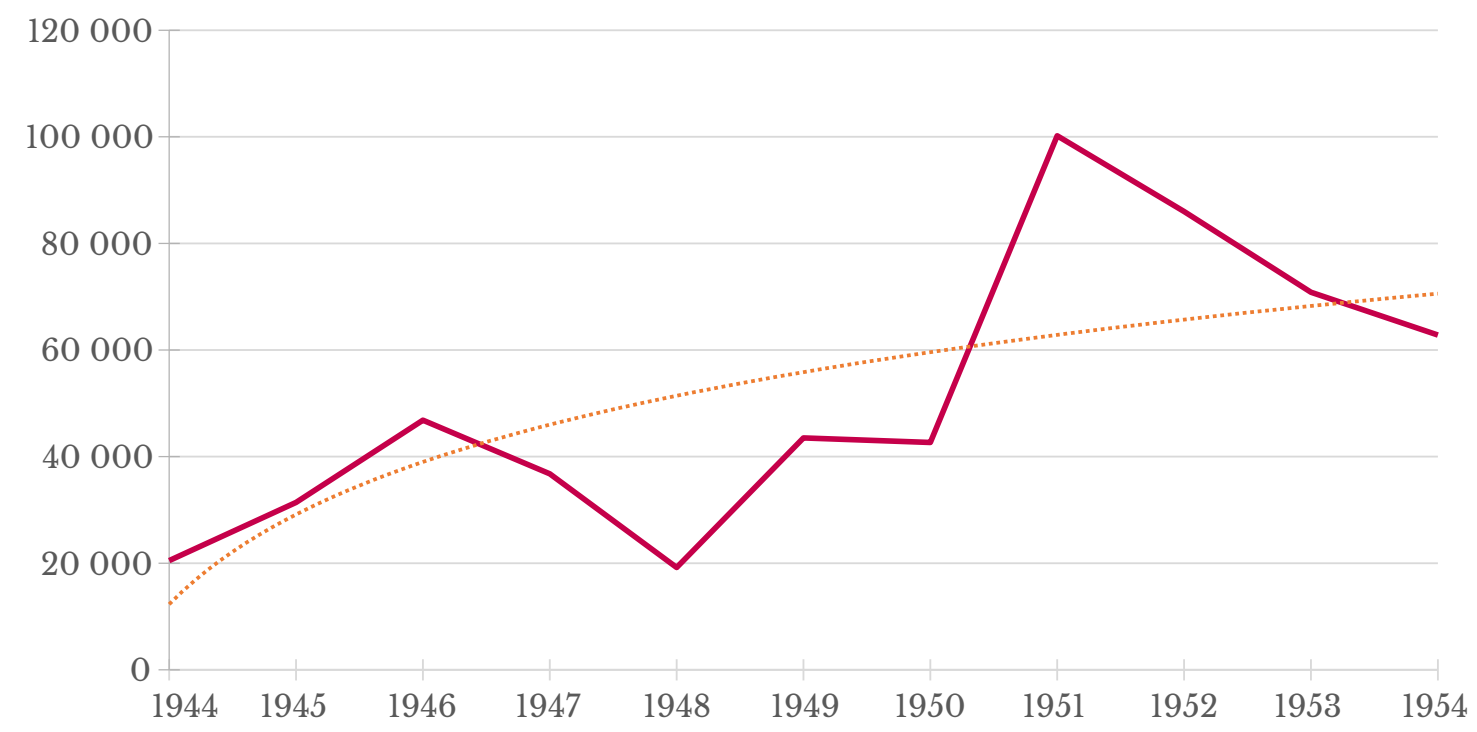

Fuente: elaboración propia con base en Dehais (2000).

leño desempeñó un papel importante en la consolidación del comercio exterior nacional en varios rubros agropecuarios, la participación de las exportaciones nacionales de manzanas ya había sido inestable en los años posteriores a la segunda guerra mundial (Rossini y Scott, 1961). Puede asegurarse que los agentes líderes, nucleados en el oligopsonio nacional, perfilaron nuevamente el circuito productivo (al estilo del monopolio inglés) hacia los mercados de ultramar en detrimento del mercado interno, configurando una estructura de penetración de los mercados europeos y brasileño.

Rendimientos estables de los productores primarios bajo predominio del oligopsonio nacional durante el peronismo

$\mathrm{Al}$ igual que en la etapa anterior, los productores se relacionaban con sus únicos compradores por medio de la modalidad a consignación, es decir, el productor recibía el valor de su cosecha, por parte del empacador y comercializador, luego de la liquidación final en el mercado interno o internacional. Esta forma de recuperar la inversión y de la ganancia esperada generaba un traslado del riesgo a manos de los productores primarios, quienes además perdían toda injerencia sobre la determinación del precio total, supeditando su sustentabilidad económica al funcionamiento del sector intermedio y final. Así, los productores independientes cedían estructuralmente el poder de negociación y, en consecuencia, comenzaron a ceder parte de los excedentes, logrados en la etapa anterior, al capital oligopsónico nacional (Jong, Tiscornia y Bandieri, 1994).

Esta interrelación gestada al interior del circuito frutícola y heredada en el tiempo provocó inevitablemente una tendencia asimétrica entre el eslabón primario y el resto de la cadena de valor, lo cual generó un deterioro estructural en el poder de negociación de los productores primarios. 
A la luz de los hechos, se puede determinar que el capital inglés optó por brindar un escenario de buenos retornos al sector primario con el objetivo principal de desarrollar esa arista de la producción frutícola. Por el contrario, las empresas nacionales que reemplazaron a la AFD optaron por explotar su posición dominante desde la comercialización. Estas firmas aprovecharon la inercia gestada en la etapa anterior, pero no operaron de manera significativa en la apertura de nuevos mercados, y tampoco evidenciaron un plan activo de inversiones en tecnología. Por su parte, con el correr de los años, la concepción empresaria basada en una evidente ideología mercantilista acentuó las tensiones estructurales del circuito y en forma paulatina deterioró la tasa de ganancia de los productores. La interrelación entre los agentes principales en esta etapa y los productores primarios se configuró en términos concretos de dependencia, dado el control exclusivo de los precios pagados por las manzanas y las peras; se produce así una situación de riesgo en cuanto a la sustentabilidad económica y social del circuito, puesto que más de la mitad de la producción (cuya media se ubicaba en 318000 toneladas de fruta durante el periodo 1944-1954) era producida por explotaciones inferiores a las diez hectáreas.

En el mismo esquema de análisis del periodo precedente se puede evidenciar -como dato referencial de la época- que tanto los precios pagados al productor como los costos totales de producción (incluyendo la tierra y las mejoras) evolucionaron de manera similar, lo que muestra una sensible baja respecto a la etapa del predominio inglés. La última temporada del periodo analizado, 1954-1955 - a la que este trabajo considera representativa dados los niveles normales de producción y un despacho de aproximadamente $30 \%$ a los mercados internacionales-, revela una tasa de ganancia sobre capital de $25.9 \%$, complementada con una tasa interna de retorno de $9.3 \%$ anual (en cinco temporadas) y una tasa de beneficio neto sobre ventas de $55.8 \%$ anual (véase gráfica 5); valores similares a los resultantes en el periodo anterior, que se ubicaron en 27.8, 55.5 y $12 \%$, respectivamente (véase anexo 1). Es importante destacar que esta tendencia estable de la condición económica de los productores se refiere a la realidad particular que la región valletana experimentó en ambos periodos; en lo que respecta a la misma temporada en otras regiones productoras de fruta, la situación se diferenció notablemente de la expresada. Para ilustrar el caso, en la provincia de Buenos Aires un productor frutícola podía aspirar a obtener -como máximo- la mitad del beneficio económico citado. La diferencia sustancial radicaba en la capacidad de riego de la región y su consecuente rendimiento productivo por hectárea. ${ }^{4}$

Por su parte, la fuerte devaluación experimentada entre 1949 y 1951 generó un aumento notable del costo de vida y de los costos de producción de los agentes afincados en la región; sin embargo, a su vez la buena cotización de los mercados pudo compensar el posible deterioro. Esta secuencia de puja devaluatoria - por parte de diversos sectores, incluidos los productores primarios- y consiguiente aumento de costos (de producción y de vida) se replicaría de modo sistemático en las siguientes décadas, estableciendo una forma de dependencia consolidada hacia las empresas comercializadoras-empacadoras, que fortalecieron su poder de negociación frente a los demás agentes del circuito frutícola.

${ }^{4}$ La Chacra, julio de 1956, pp. 19 y 107. 


\section{GRÁFICA 5. RENDIMIENTOS DE PRODUCTORES. COMPARACIÓN TEMPORADAS 1938-1939 Y 1954-1955}

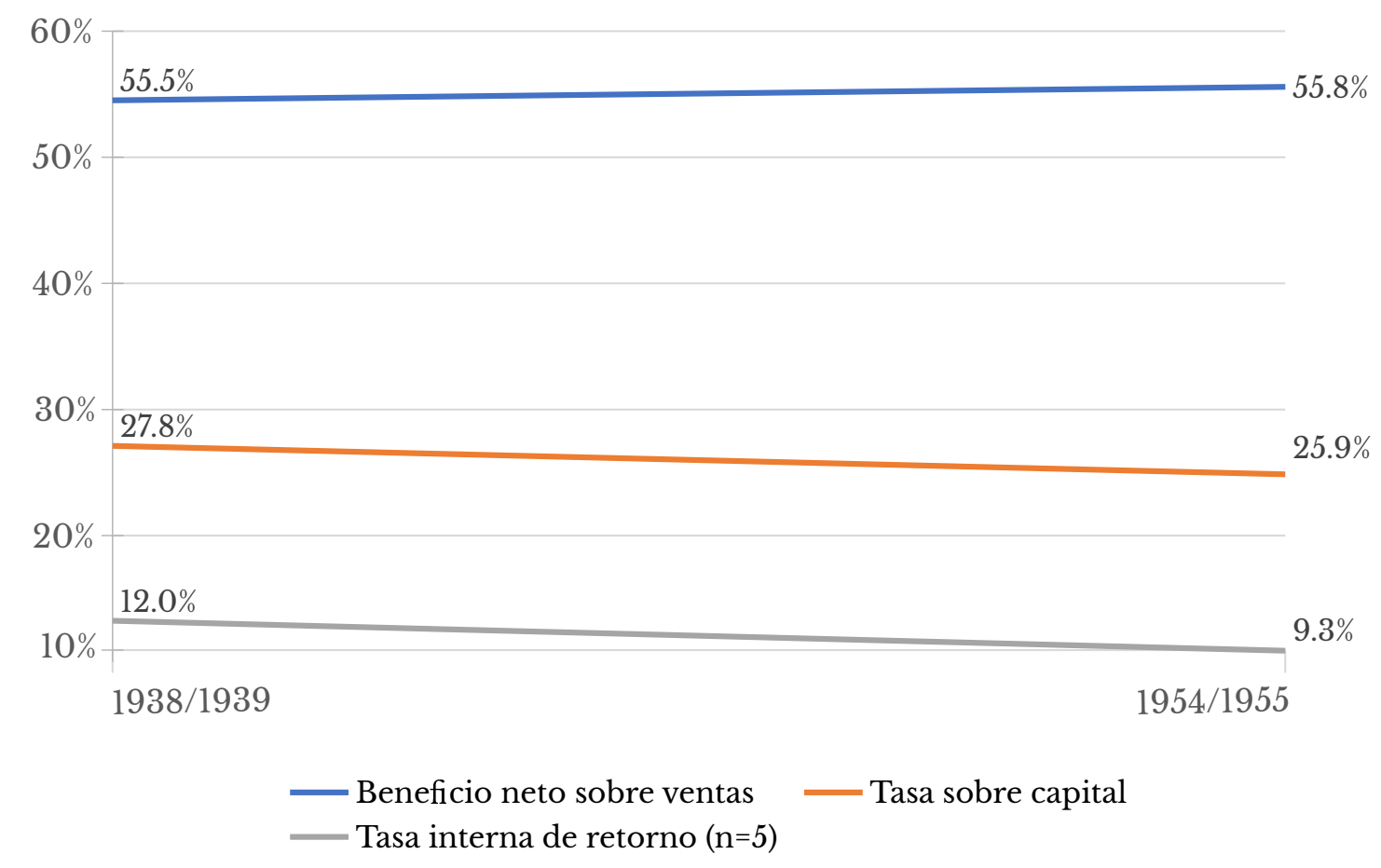

Fuente: elaboración propia con base en Vera (2017).

\section{PRIMERAS EVIDENGIAS DEL DETERIORO ESTRUGTURAL DE LA FRUTICULTURA}

Luego del Plan de Estabilización de 1952, orientado a reactivar la actividad mediante políticas económicas de perfil ortodoxo, el ejecutivo procuraba un cambio en el régimen de acumulación hacia una configuración intensiva. Los años posteriores al plan de ajuste y estabilización de 1952 se interpretan como tres subperiodos dentro de la escalada de irregularidades que desencadenaron en la inflación de 1989. En lo que respecta a este trabajo, y de acuerdo con Neffa (1998), la década posterior al golpe de Estado de septiembre de 1955 corresponde a una parte del primer subperiodo, que completo abarca el periodo 1952-1976, donde se alternaron gobiernos militares y democráticos bajo la bandera de la UCR, ambos enfrentados a la dinámica stop and go de la economía nacional. La consecuencia de una industrialización incompleta y la alternancia de políticas económicas heterogéneas generaron una continuación y diversificación del proceso de industrialización, con rasgos introvertidos, pero con una creciente apertura comercial mediante exportaciones tradicionales y no tradicionales. Previo a la salida abrupta de Juan Domingo Perón del gobierno por el golpe cívico militar de la revolución libertadora, se habían generado instancias de consenso, entre diferentes sectores dominantes y el Estado nacional, a fin de delinear una estrategia de salida a las limitaciones de la etapa peronista de la industrialización por sustitución de importaciones. 
Sumado a la promulgación de la Ley de Inversiones Extranjeras, se puede agregar -como hecho simbólico- el Acuerdo Nacional de Productividad acontecido en 1954, que contemplaba la necesidad de mayores inversiones en función de una exigencia de productividad de los trabajadores.

En cierta forma, la nueva planificación estratégica nacional impactó en la región del Alto Valle, donde se evidencia una fuerte inversión en bienes de capital, específicamente relacionados con el aumento en la capacidad de frío. Los rezagos tecnológicos heredados en relación con la fruticultura se daban en dos aspectos centrales: el primero referido al deterioro del transporte ferroviario de la producción, el segundo vinculado con la falta de inversión privada o pública en el aumento de la capacidad de empaque y frío. Ambas situaciones se vieron agravadas luego de la nacionalización del ferrocarril y, consecuentemente, de la AFD, por lo cual se profundizaba un escenario negativo para el poder de negociación de los productores, compensado parcialmente con la organización cooperativa. La Distribuidora Argentina de Frutas (ex AFD) había perdido su eficiencia en las actividades de empaque y comercialización debido al peso burocrático de sus funciones operativas (véase Vapñarsky, 1983); esto se condice con el posterior reemplazo total del sistema de transporte ferroviario por el de camiones a partir de 1966. En esta etapa, el circuito frutícola mostró una importante participación en el PBG de la provincia de Río Negro; en 1960 mostró un aporte de $16.02 \%$ al total de la región y $55.6 \%$ al sector agropecuario. Cabe destacar que el PBG provincial creció $25.71 \%$ entre 1955 y 1965 , por lo tanto, el peso de la fruticultura en la estructura mantuvo un lugar privilegiado como una actividad de alto dinamismo. A partir de 1965 las actividades extractivas promovieron el mayor dinamismo para el crecimiento del PBG. De este modo se puede afirmar que durante la década de $1950 \mathrm{el}$ principal motor del crecimiento fue la actividad frutícola, mientras que en la década de 1960 el petróleo representó la principal actividad para el crecimiento de la economía provincial.

\section{Provincialización del territorio nacional. Impacto regional}

Uno de los objetivos del gobierno peronista en cuanto a la ampliación de ciudadanía política fue incorporar al esquema federal a diversos espacios territoriales que se habían desempeñado bajo la órbita nacional. Ruffini (2005) sostiene que "con esta decisión el peronismo clausuraba una larga etapa territorial signada por restricciones al ejercicio de la ciudadanía política para los habitantes de los territorios nacionales, incorporándolos con plenos derechos al Estado nacional" (p. 132). En ese marco estratégico, el 15 de junio de 1955 el Congreso de la Nación sancionó la Ley 14.408, promulgada por el poder ejecutivo nacional el día 28 del mismo mes: se creaba así la provincia de Río Negro junto con las de Neuquén, Formosa, Chubut y Santa Cruz. Esta nueva configuración del territorio nacional operaría de lleno en los gobiernos posteriores a la revolución libertadora, alternados entre la dictadura militar de Eduardo Lonardi y Pedro Aramburu, entre 1955 y 1958; el gobierno de transición de José María Guido, entre 1962 y 1963, y los gobiernos de la Unión Cívica Radical de Arturo Frondizi, entre 1958 y 1962, y Arturo Illia entre 1963 y 1966.

En cuanto a la región del Alto Valle, se puede observar que el crecimiento de la población continuó expandiéndose hasta fines de la década de 1960; la región no deja de ser atractiva, su población crece $64 \%$, pasando de 89250 a 146771 habitantes. Las aglomeraciones productivas cercanas al Sistema Mayor de Riego tuvieron mayor crecimiento respecto al resto.

Es indudable que el aumento de la actividad promovió un atractivo para el asentamiento de nuevos pobladores. La producción de fruta de pepita (total de manzanas y peras) en periodo 1955-1965 creció $61 \%$, pasando de 271950 a 438730 toneladas, aumento explicado exclusiva- 
mente por la producción de manzanas, puesto que la producción de peras evidenció una tendencia estable (véase gráfica 6). La importancia de la manzana y la pera del Alto Valle en la demanda interna y externa explica las variaciones nacionales de las mismas especies, ponderando -como se dijo- el peso específico de las manzanas en el volumen total producido. Cabe recordar que la matriz productiva regional y nacional se había volcado sustantivamente a la producción de manzanas a partir del año 1948. Para ilustrar la situación en lo que respecta a la región en ese mismo año, la producción de pomáceas estuvo distribuida en la mitad para cada especie (manzanas y peras); a partir de ese año la tendencia muestra un distanciamiento entre la participación de las especies, llegando a estructurar una relación promedio de $80 \%$ manzanas y $20 \%$ peras.

\section{GRÁFICA 6. PRODUCGIÓN DE MANZANAS Y PERAS EN LA REGIÓN ALTO VALLE.} AÑOS 1955-1966

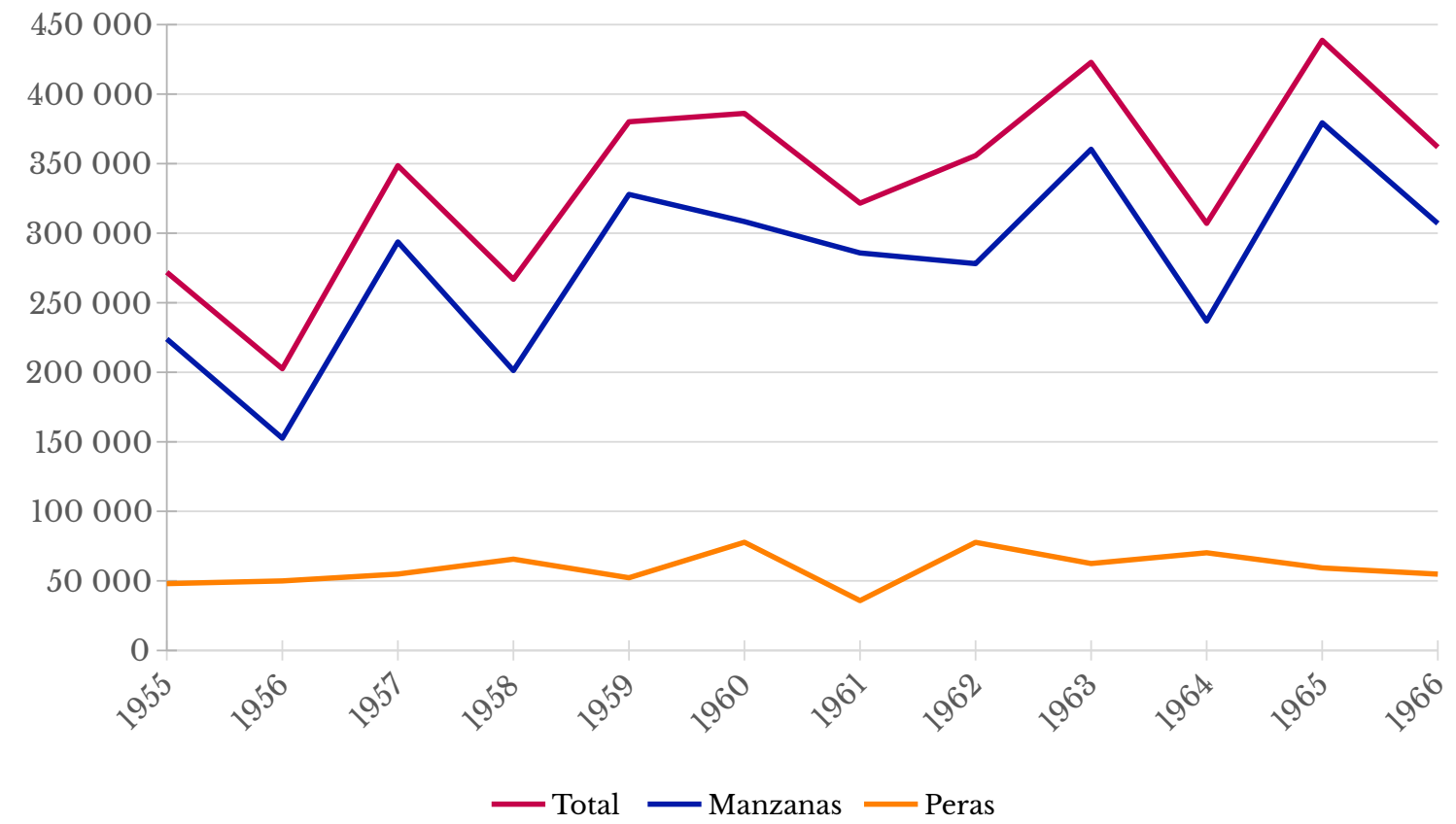

Fuente: elaboración propia con base en Dehais (2000).

En este escenario regional, la producción de manzanas representó en promedio casi $70 \%$ de la producción nacional, mientras que la producción de peras aportó $60 \%$. Los agentes protagonistas de la década previa al ciclo agroindustrial ${ }^{5}$ continuaron una senda de explotación de carácter oligopsónico-oligopólico nacional, pero a diferencia de la década peronista, en este segmento puede evidenciarse el impacto de las inversiones privadas -con apoyo estatal- en la capacidad frigorífica instalada en la región, pasando de cuatro a 30 establecimientos industriales.

${ }^{5}$ Este trabajo adopta el enfoque de César Vapñarsky (1983), quien establece que el ciclo agroindustrial comienza en el bienio 1966-1967, cuando finalizan las obras viales de la ruta entre Bahía Blanca y el Alto Valle (tramo Río ColoradoChoele Choel). 
El papel del estado provincial se perfiló como un agente dinamizador de la economía con la construcción de una estructura legal que incidió en el plano financiero y laboral; ejemplos de ello son la creación del Banco de la Provincia de Río Negro (1960) y la creación de la Corporación de Productores Frutícolas (en 1961 mediante la Ley 281). La región entraba en una etapa de alta inversión en la capacidad de frío, con la que absorbió más de $11 \%$ de la producción en las instalaciones frigoríficas. La necesidad de las empresas nacionales líderes del circuito frutícola se sustentaba en la alta producción de la región en un corto tiempo (la mayor producción se da estructuralmente en el primer cuatrimestre del año); la capacidad de frío permitía la conservación de la fruta en el tiempo y el armado de un stock más estable, lo cual impactaba positivamente en el poder de negociación del eslabón de los agentes con capacidad de comercializar. Con este paso sustantivo en la tecnología aplicada al eslabón intermedio de transformación, el circuito perfilaba una tendencia de regionalización en las actividades de empaque y frío, tendencia que se acentuaría en el ciclo agroindustrial de la fruticultura. La producción valletana consolidó su aportación preponderante en la producción nacional de manzanas y peras, lo que representó -en promedio- más de $65 \%$ del total producido entre 1955 y 1965. A su vez, los volúmenes exportados mantuvieron un peso protagónico en el sector y aportaron -en promedio- $95 \%{ }^{6}$ al total de las exportaciones nacionales, las cuales evidenciaron una acentuada tendencia positiva en el periodo analizado.

Entre 1955 y 1965, la particularidad de la producción frutícola regional se centró en su desarrollo y su comecialización -por parte de las empresas líderes- hacia los mercados de ultramar. La gráfica 7 muestra como se ahondó en la tendencia negativa sobre la relación de los despachos al mercado interno y a la exportación. La extraversión del circuito productivo frutícola se intensificó luego de los gobiernos peronistas, cuando la mayor parte de la producción valletana llegó a depender de las exportaciones. Esta configuración permite determinar que los mercados de ultramar generaron un incentivo claro hacia el eslabón productivo, aunque sin generar condiciones favorables para los productores primarios. La internalización de hábitos productivos hacia los estándares de calidad exigidos por las empresas comercializadoras promovió una evolución de las formas productivas para satisfacer dicha demanda externa. Cabe destacar que la extrema dependencia de un circuito productivo hacia los mercados de ultramar conlleva una lógica de acumulación dependiente de variables exógenas, lo que genera dificultad para intervenir y lazos que resultan complejos de controlar institucionalmente. Eso posibilita buenas oportunidades para determinados agentes, pero genera una morfología productiva vulnerable y sensible a determinadas variables externas, como puede ser la devaluación de la moneda de un país comprador en el valor del stock exportable.

Este crecimiento sostenido determinó la consolidación de la tendencia exportadora nacional de manzanas y peras. La región valletana se constituyó predominante en cuanto al stock necesario para abastecer la demanda externa. A medida que la configuración profundizaba su tendencia inercial del primer periodo, correspondiente al monopolio inglés, el consumo per cápita nacional de manzanas y peras comenzaba una tendencia decreciente. Si analizamos los extremos de la década, podemos observar que para 1955 la demanda interna absorbía $14.7 \mathrm{~kg}$ de manzanas y $4.5 \mathrm{~kg}$ de peras por persona, mientras que para 1965 los valores de consumo individual se ubicaron en $12.8 \mathrm{~kg}$ de manzanas y $1.9 \mathrm{~kg}$ de peras por persona. Sobre la tendencia en el consumo interno de manzanas y peras, es importante destacar que existe un consenso unánime en la progresiva caída de estos valores en las décadas posteriores, esto supone que la valorización del producto y la producción se configuró en tendencia creciente y dependiente en la demanda externa, generando

${ }^{6}$ En 1964, 95 \% de las exportaciones nacionales fue aportado por la producción valletana (Revista Anales, 1964). 
GRÁFICA 7. RELACIÓN MERCADO INTERNO SOBRE EXPORTACIONES. ESTIMACIONES. ALTO VALLE DEL RÍO NEGRO Y NEUQUÉN, 1955-1966

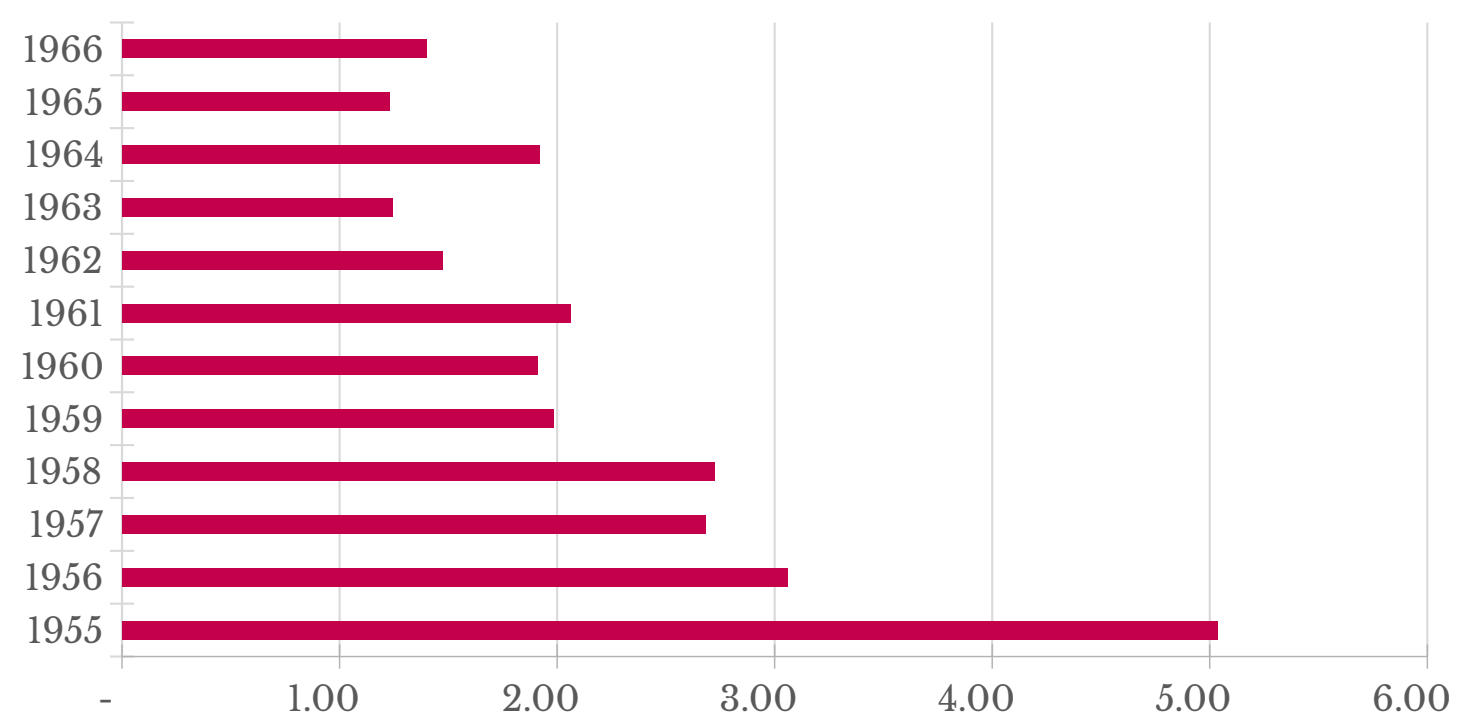

Fuentes: elaboración propia con base en Berberian (1967), Dehais (2000) y Wetzler (1941).

un escenario de necesidades en cuanto a fortalecer la competitividad mediante la optimización de los factores empresariales, donde el trabajo -aportado en este caso por los productores primarios afincados en la región- es una variable susceptible al ajuste.

Otro aspecto de gran impacto a nivel regional fue la valoración de las hectáreas en la zona de riego mejoradas para producir. La estimación efectuada a partir de datos históricos evidencia que las hectáreas para producción rondaban entre 360 y 370 dólares para la temporada de 1938-1939, y las mismas tierras se valuaron en 3400 y 3450 dólares para la temporada 1964-1965. La explicación se debe exclusivamente al interés por parte del sector privado en la actividad, a la que buscaba concentrar verticalmente. Asimismo, cabe destacar que el sistema de riego no evolucionó significativamente en esta etapa: a las 57422 hectáreas existentes, solo se le sumaron 3000 hectáreas bajo riego hasta el año 1968 sin alterar en demasía la situación de números de parcelas por subdivisión (Kloster, 1988).

\section{Rendimientos de productores en un contexto de competencia internacional}

Ante los cambios descritos anteriormente, al retomar el enfoque sobre la situación de los productores primarios de la región valletana, enmarcada en una relación asimétrica entre los chacareros frutícolas y las empresas líderes del circuito, ${ }^{7}$ puede asegurarse que se inició una tendencia desfavorable en cuanto a los rendimientos económicos de las producciones primarias. Jong (2010) argumenta que esta situación se relaciona con la irresponsabilidad de las empresas líderes, que optaron por el "negocio fácil", aun resultando ineficientes, mientras no tuvieron un escenario de competencia con otros países productores. Si bien este trabajo coincide -en parte- con esta aseve-

${ }^{7}$ Representadas en este trabajo como el oligopsonio-oligopolio nacional 
ración, no concuerda en la unilateralidad de los fenómenos; antes bien, se pondera la construcción histórica de la configuración del circuito frutícola, que desde diversas esferas fue pergeñando comportamientos al interior de cada eslabón de la cadena de valor.

A partir de 1960, la aparición de la competencia por parte de países del hemisferio sur, como Sudáfrica y Nueva Zelanda, precipitó una acción mercantilista intensa de las empresas líderes sobre los productores, con el afán de mantener su posición en el mercado externo y conservar la plaza del mercado interno. Las empresas nacionales líderes del circuito gozaban, hasta esta etapa, de cierta comodidad para la captación de mercados de ultramar hasta la aparición de estos países competidores, quienes generaron en menos de una década transformaciones en la producción y el acondicionamiento, posibilitando así un progresivo aumento de la producción para la exportación hacia los mercados europeos (Landriscini, Preiss, Raggi, Rama y Rivero, 2007). Evidentemente, esto provocó modificaciones al interior del circuito frutícola nacional en tres aspectos fundamentales: 1) rigidez en la negociación de los precios pagados a los productores; 2) reorientación de las exportaciones, y 3) la indispensable inversión tecnológica para la mejora en la calidad y en la conservación.

En una década, las exportaciones de Nueva Zelanda, Australia y Sudáfrica se incrementaron en $82 \%$ (total manzanas y peras de los tres países), pasando de exportar 222000 a 406000 toneladas, teniendo como principal comprador al continente europeo. En el mismo periodo, la exportación nacional total de manzanas y peras se expandió en $30.4 \%$, de la venta a Brasil y Europa principalmente, pasando de 460000 a 600000 toneladas. Si bien el volumen total de exportaciones nacionales (explicado en más de $90 \%$ por la producción del Alto Valle) se elevó de manera sostenida, el incremento acelerado de la competencia externa ubicaba al sector comercial frutícola en una situación inédita hasta esta década.

Si analizamos la condición de los agentes regionales primarios, se observa un deterioro abrupto de las tasas de rendimiento en esta etapa. Al ubicar el cotejo en la temporada del año 1965 , previa al inicio del ciclo agroindustrial, se puede comprobar una tasa sobre capital de $6.1 \%$, la cual contrasta notablemente con aquel $25.9 \%$ de la etapa anterior; por otra parte, el beneficio neto sobre ventas arroja una tasa de $25.9 \%$, mostrando una caída notable respecto a la etapa anterior que evidenciaba un $55.5 \%$ anual; para complementar el análisis, es notorio un deterioro en la tasa interna de retorno para cinco temporadas, la cual se ubica -en valores negativos- en $29.9 \%$, una caída notable si tenemos en cuenta el $9.3 \%$ de la temporada 1954-1955 (véase gráfica 8 y anexo 1). Esta situación pudo percibirse en el devenir de la década analizada y es por ello que determinados sectores de productores primarios pujaron por la aparición de una entidad que resguardara su condición económica.

En 1956 se constituyó la Federación de Productores de Fruta de Río Negro y Neuquén, y al mismo tiempo se comenzó a gestar la idea de crear una corporación regional, autónoma, dirigida y administrada por productores. En los inicios de 1961 se realizaron las primeras tratativas entre la federación y funcionarios de la provincia de Río Negro, y en la primera quincena de abril del mismo año se fijó la idea de encarar la formación de una entidad de fomento bajo estos principios. Luego de una etapa de diagnóstico sobre la situación de la fruticultura, el 19 de diciembre de 1961 se aprobó la Ley 281, que sancionaba la creación de la Corporación de Productores Frutícolas, publicada en el Boletín Oficial (31 de enero de 1962, núm. 72). El autor del proyecto de ley fue el entonces diputado Julio Rajneri, propietario del diario Río Negro. 


\section{GRÁFICA 8. RENDIMIENTOS DE PRODUCTORES. COMPARACIÓN TEMPORADAS} 1938/1939, 1954/1955 Y 1964-1965

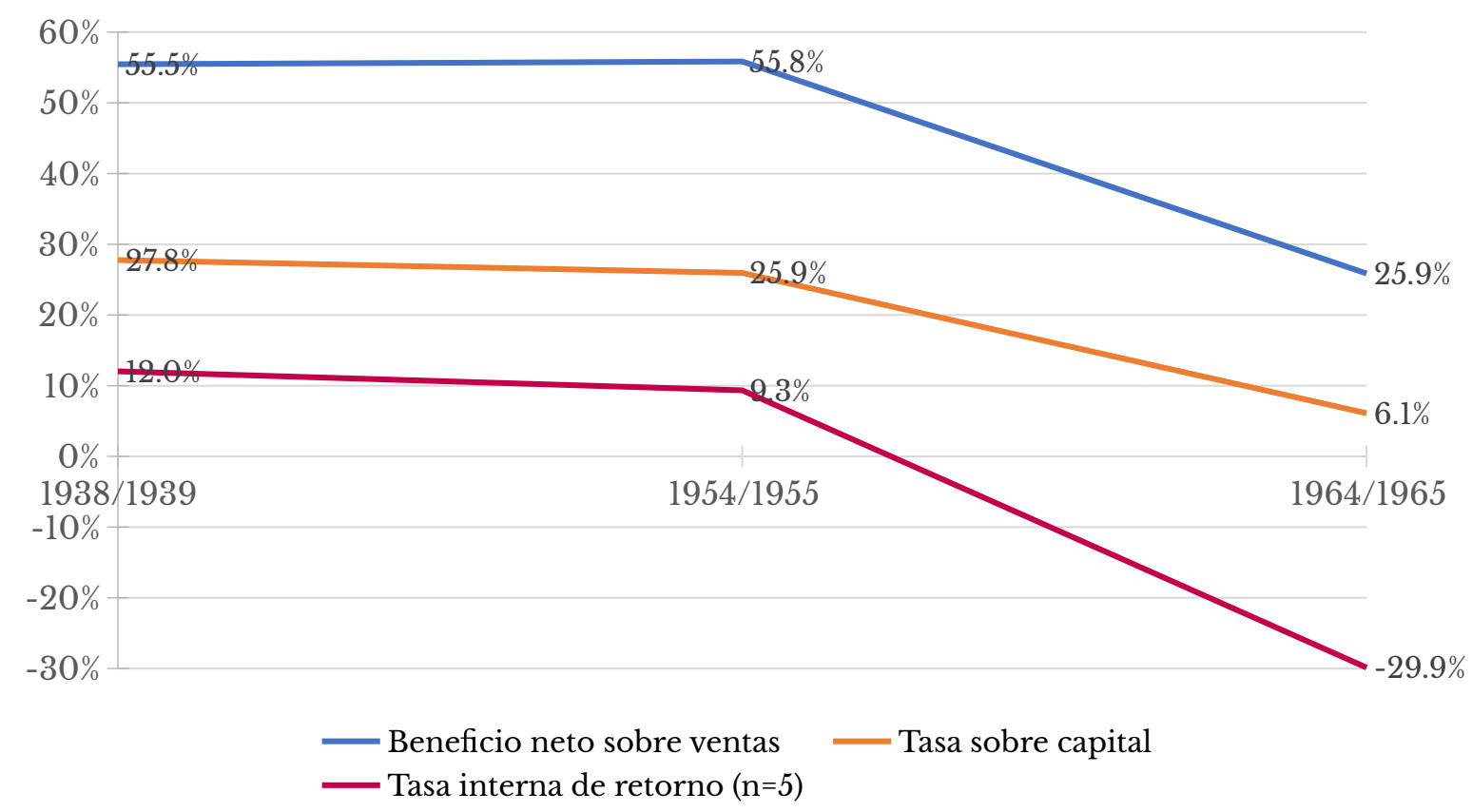

Fuente: elaboración propia con base en Vera (2017).

Otro fenómeno explicativo del deterioro en los ingresos de los pequeños productores se debió al cambio tecnológico requerido para una configuración agroindustrial de la producción. Sin duda, estas innovaciones requerían financiamiento, y parte de ese excedente fue obtenido, por un lado, gracias a los buenos precios internacionales mencionados anteriormente, y por otro, mediante el manejo de precios pagado a los pequeños productores, quienes en forma acelerada (luego del periodo peronista) fueron perdiendo gran parte de su rentabilidad. Las sucesivas devaluaciones generaron, al interior de la estructura de costos de los productores, un aumento pronunciado; el efecto del ciclo stop and go -en los términos de Diamand (1972)- tradujo los corrimientos cambiarios en aumentos de precios mayoristas y minoristas, los cuales en la evidencia desarrollada incrementaron en $1471 \%$, mientras que los ingresos -ante la configuración asimétrica con las empresas comercializadoras- sólo aumentaron 860 por ciento.

\section{Conclusiones}

La importancia de las tres décadas abarcadas en el presente trabajo se vincula con que a partir de ellas pudieron gestarse tendencias estructurales que condicionaron al circuito frutícola hasta la actualidad. La relación asimétrica entre productores y empresas líderes posibilitaron un escenario de vulnerabilidad de los pequeños y medianos productores en cuanto a las posibilidades de ne- 
gociación y eventualmente de disputa por el excedente generado en la actividad; en este sentido, esta relación puede dimensionarse como una relación de dependencia encubierta entre pequeños productores y empresas comercializadoras-empacadoras (oligopolio-oligopsonio).

El quiebre evidenciado a partir de la temporada 1954-1955 permite detectar el deterioro de las condiciones económicas (y consecuentemente sociales) de los productores primarios, quienes relegaron gran parte del excedente generado por el circuito frutícola valletano, traducido en una baja de rendimientos. Este condicionamiento novedoso para la temporada señalada se replicaría de manera sistemática en las temporadas siguientes. Para ilustrar la situación basta citar el cálculo realizado por Jong (2010), donde una chacra de similar superficie y rendimiento a las analizadas en este trabajo arrojaba una tasa de ganancia sobre capital de $3.7 \%$ para la temporada 1993-1994. Si bien, diferentes razones pudieron incidir en la toma de decisiones de las empresas nacionales comercializadoras-empacadoras en relación con comprimir la economía del eslabón primario - por ejemplo, la aparición de la competencia extranjera-, no cabe duda que la estructura de la cadena de valor fue en gran medida el escenario que permitió este comportamiento. Las reglas establecidas por medio de las tendencias estructurales, construidas en el tiempo, generaron instancias de desigualdad al interior del circuito productivo de la fruta en el Alto Valle de Río Negro.

En cada una de las etapas analizadas pueden identificarse diferentes características configuradas a partir de hechos significativos. La primera etapa se relaciona con la planificación original del capital inglés, la cual presenta una tendencia clara de aumento de la producción y de los despachos a los mercados de ultramar. Ante la caída de los mercados internacionales en el contexto de la segunda guerra mundial, se puede destacar una segunda etapa, donde la tendencia productiva sigue siendo positiva, pero se evidencia una presencia sustantiva del mercado interno para compensar la caída de la demanda externa. En tercer lugar, a partir de 1944 y ante la recuperación de la demanda internacional postsegunda guerra mundial, la tendencia inicial retoma su cauce original y se acentúa, por un lado, el crecimiento de la producción de la región valletana, y por otro, la orientación de los stocks frutícolas hacia los mercados externos (europeos y brasileños, principalmente). Hacia los últimos años de este análisis, el reparto entre mercado interno y exportaciones tiende a distribuirse de manera equitativa, lo que deja en evidencia una particular configuración del circuito productivo regional como respuesta a la demanda y a los estándares de calidad de los mercados extranjeros.

Por otro lado, es importante destacar que los saltos del precio de la moneda nacional generaron, sin lugar a dudas, un aumento de los costos de producción y, como consecuencia, el deterioro de las tasas de rendimiento explicadas anteriormente. A partir del bienio 1954-1955 el impacto de las devaluaciones deteriora las condiciones de los productores primarios frutícolas; la imposibilidad de negociar el precio pagado por la fruta ante las empresas comercializadoras, que detentaron su poder de negociación, estructuró una tendencia regional desfavorable para la sustentabilidad económico-social del agente productivo central y característico de la región valletana. Dicho esto, puede asegurarse que el afincamiento local de los agentes intervinientes en los diferentes eslabones del circuito-complejo productivo puede generar tendencias favorables para la posibilidad de desarrollo regional, y posibilitar la construcción -en el devenir de la historia- de un sentido de identidad respecto al espacio habitado, así como establecer estrategias propias desde un lugar determinado, evitando supeditar la planificación estratégica de su región por parte de agentes extrarregionales (nacionales y extranjeros). En el caso analizado, los agentes extrarregionales al colonizar 
diferentes instancias productivas provocaron configuraciones específicas que responden a sus intereses particulares, generando así la posibilidad de estructurar fuerzas desiguales de apropiación del excedente.

La evidencia volcada en este trabajo muestra que la actividad frutícola valletana fue históricamente pensada por agentes extrarregionales -extranjeros y nacionales-, lo que generó una asimetría entre los diferentes eslabones, al afirmar el poder de negociación extrarregional y al mismo tiempo vulnerar las posibilidades de apropiación del excedente por parte de los productores primarios regionales. Es importante destacar que la captación de la renta resulta un mecanismo dinámico, imprescindible a la hora de generar condiciones favorables para los agentes afincados en las regiones; la forma que esta adquiera en favor de determinados agentes depende de las relacionespujas políticas en determinado momento, o sea, es producto de la dinámica social acontecida.

\section{ANEXo 1}

\section{Metodología para cálculo de tasas de rendimiento}

La metodología para el cálculo de las tasas correspondientes al rendimiento económico de los pequeños y medianos productores se basó en los avances bibliográficos correspondientes a Jong, Tiscornia y Bandieri (1994), de Susana Bandieri y Graciela Blanco (1998). El mismo cálculo ha sido replicado en Jong (2010) y en Vera (2017).

A su vez, se procedió al cálculo de tres tasas diferentes para cada temporada analizada (véase cuadro 2): $a$ ) tasa de ganancia sobre capital: resultante del cociente entre el beneficio neto sobre ventas y la sumatoria de los flujos de fondos negativos + el capital desembolsado, respetando la metodología de Jong, Tiscornia y Bandieri (1994); $b$ ) tasa de beneficio sobre ventas: resultante de las ventas de la temporada deducidos sus egresos y amortizaciones, y $c$ ) tasa interna de retorno en cinco temporadas: resultante de la actualización (valor presente) de los flujos de fondos proyectados para cinco años.

\section{CUADRO 2. ESTIMACIONES DE RENDIMIENTO DE LOS PRODUCTORES (HASTA DIEZ HECTÁREAS)}

\begin{tabular}{lccc}
\hline & \multicolumn{3}{c}{ Temporadas (en porcentajes) } \\
\multicolumn{1}{c}{ Concepto } & $1938-1939$ & $1954-1955$ & $1964-1965$ \\
\hline Beneficio neto sobre ventas & 55.5 & 55.8 & 25.9 \\
Tasa sobre capital & 27.8 & 25.9 & 6.1 \\
Tasa interna de retorno $(\mathrm{n}=5)$ & 12 & 9.3 & -29.9 \\
\hline
\end{tabular}

Fuente: elaboración propia.

Para cada estimación se ha respetado la validez de los datos históricos, teniendo en cuenta las siguientes consideraciones: $a$ ) para la temporada 1938-1939 se han promediado nuevamente los precios pagados a los productores, con base en los datos históricos referenciados en Wetzler (1941), los cuales arrojaron un ajuste de 0.005 pesos. Por lo tanto, la tasa de ganancia sobre capital se ajustó de $27.2 \%$ (calculada por Bandieri y Blanco, 1998) a $27.8 \%$, en relación con el trabajo citado anteriormente; $b$ ) para las temporadas 1954-1955 y 1964-1965 se utilizaron los precios 
pagados a productor de igual manera para manzanas y peras, dada la paridad en las cotizaciones históricas. Ambas referencias son producto de diferentes fuentes; para el año 1955 se relevó el dato de la revista Chacra (julio de 1956, p. 19), y para el año 1965 se tuvo en cuenta el dato estimado por Berberian (1967), con base en información de la Secretaría de Estado de Agricultura y Ganadería de Argentina, por medio de la Dirección de Frutas y Hortalizas, y revista Chacra (abril de 1966, p. 28), con base en un estudio del ingeniero Vacarezza del año 1965; c) la distribución para las temporadas 1954-1955 y 1964-1965 de la producción-comercialización se ajustó de manera coherente con la distribución productiva regional de cada momento, dada la transformación de la superficie cultivada; $d$ ) para el cálculo correspondiente a las temporadas 1954-1955 y 19641965 se partió de los valores históricos pagados a productores, tomando como referencia el cajón de manzana estándar. Si bien en la temporada 1938-1939 el precio pagado a los productores por manzanas y peras era visiblemente diferente, cabe destacar que en las temporadas posteriores a la nacionalización de la AFD (1948), los precios se establecieron de manera similar. Por otro lado, la producción de manzanas evolucionó por encima de la producción de peras, siendo la especie de mayor peso productivo en la región; $e$ ) para la valorización de las hectáreas productivas y sus respectivas mejoras, se estimó un crecimiento en dólares - de la hectárea- tomando como referencia el importe inicial (de ambos conceptos) del año 1939 (367.3 dólares) y un dato histórico extraído de Berberian (1967) para el año 1967 correspondiente (a 3428.57 dólares), y $f$ ) para los demás conceptos expresados para las temporadas 1954-1955 y 1964-1965 (siguiendo la misma metodología desarrollada para la temporada 1938-939), se efectuó una indexación por medio de una serie de índices históricos (véanse cuadros $3,4,5$ y 6 ).

\section{CUADRO 3. ESTIMACIONES DE RESULTADOS}

\begin{tabular}{lrrr}
\hline \multicolumn{1}{c}{ Concepto } & \multicolumn{3}{c}{ Temporadas } \\
\hline Ingresos & $1938-1939$ & $1954-1955$ & $1964-1965$ \\
Costos totales & 5875 & 198912 & 1909555 \\
Amortizaciones & 936 & 12592 & 1195587 \\
Resultado & 8479 & 111068 & 220139 \\
\hline
\end{tabular}

Fuente: elaboración propia.

Por último, cabe realizar una serie de aclaraciones sobre las indexaciones (véase cuadro 7) realizada en el respectivo cuadro 4: $\operatorname{los} \operatorname{rubros} a, f, g, h, j, k, l$ y $m$ se indexaron con el concepto 2. Los rubros $b, c$ y $d$ se indexaron con el concepto 5 . El rubro $e$ se indexó con el concepto 7 . El rubro $i$ se indexó con el concepto 4 . Los rubros $n, \tilde{n}$ y $o$ se indexaron con el concepto 1 . El rubro $p$ se indexó con el concepto 6 . El rubro $q$ se indexó con el concepto 3. 


\section{CUADRO 4. ESTIMAGIONES DE COSTOS}

\begin{tabular}{|c|c|c|c|c|c|}
\hline Rubros & & & $\begin{array}{c}\text { Total } \\
\text { temporada } \\
1938-1939\end{array}$ & $\begin{array}{c}\text { Total } \\
\text { temporada } \\
1954-1955\end{array}$ & $\begin{array}{c}\text { Total } \\
\text { temporada } \\
1964-1965\end{array}$ \\
\hline \multirow{10}{*}{ Fijos } & $\mathrm{a}$ & Poda de fructificación & 308 & 4359.3 & 71775 \\
\hline & $\mathrm{b}$ & Pulverizado con aceite & 456 & 4470.8 & 66645 \\
\hline & c & Pulverizado con arseniato & 432 & 4235.5 & 63137 \\
\hline & $d$ & $2 \%$ azufre mojable & 138 & 1353 & 20169 \\
\hline & $\mathrm{e}$ & Combustible pulverizado & 300 & 2606.4 & 18168 \\
\hline & $\mathrm{f}$ & Personal para pulverizar & 336 & 4755.6 & 78300 \\
\hline & $\mathrm{g}$ & Personal para raleo & 336 & 4755.6 & 78300 \\
\hline & $\mathrm{h}$ & Limpieza de acequias & 77 & 1089.8 & 17944 \\
\hline & $\mathrm{i}$ & Abonos verdes & 120 & 949.7 & 17646 \\
\hline & $\mathrm{j}$ & $\begin{array}{c}\text { Tareas de administración } \\
\text { y conducción de peras }\end{array}$ & 1680 & 23778.1 & 391501 \\
\hline \multirow{3}{*}{ Variables } & $\mathrm{k}$ & Cosecha de peras & 215 & 3043 & 50103 \\
\hline & 1 & Cosecha de manzanas & 184 & 2604.3 & 42879 \\
\hline & $\mathrm{m}$ & Traslado & 999 & 14139.5 & 232803 \\
\hline \multirow{6}{*}{ Indirectos } & $\mathrm{n}$ & Impuesto a los vehículos & 20 & 186.8 & 2677 \\
\hline & $\tilde{n}$ & Cánon de riego & 70 & 560.4 & 8032 \\
\hline & o & Contribución territorial & 34 & 280.2 & 4016 \\
\hline & $\mathrm{p}$ & Conservación y mejoras fundiarias & 90 & 1060.2 & 14397 \\
\hline & q & Conservación de bienes de uso & 80 & 1024 & 17095 \\
\hline & & Totales & 5875 & 75252.4 & 1195587 \\
\hline
\end{tabular}

Fuente: elaboración propia.

\section{LISTA DE REFERENCIAS}

Álvarez, E. (2012). La colonización del Alto Valle del Rio Negro (Neuquen) en Argentina: Ferrocarril, obras hidráulicas y electricidad y consolidar del poblamiento. Simposio internacional globalización, innovación y construcción de redes técnicas urbanas en América y Europa, 18901930. Simposio internacional globalización, innovación y construcción de redes técnicas urbanas en América y Europa, 1890-1930, 1-20. Barcelona. Recuperado de http://hdl.handle.net/2117/ 17283

Bandieri, S. (2005). Historia de la Patagonia. Buenos Aires: Editorial Sudamericana.

Bandieri, S. y Blanco, G. (1991). La fruticultura en el Alto Valle de río Negro. Auge y crisis de una actividad capitalista intensiva. Revista de Historia, 2, 127-141.

Bandieri, S. y Blanco, G. (1998). Pequeña explotación, cambio productivo y capital británico en el Alto Valle del Río Negro (1900-1948). Quinto Sol, 2, 25-63. Dor: 10.19137/qs.v2i0.7

Berberian, C. (1967). Necesidad de una financiación adecuada para la producción y exportación de peras y manzanas (Tesis de doctorado). Universidad de Buenos Aires, Argentina. 
GUADRO 5. ESTIMACIONES DE AMORTIZACIONES

\begin{tabular}{|c|c|c|c|c|}
\hline Rubros & & $\begin{array}{c}\text { Total } \\
\text { temporada } \\
\text { 1938-1939 }\end{array}$ & $\begin{array}{c}\text { Total } \\
\text { temporada } \\
1954-1955\end{array}$ & $\begin{array}{c}\text { Total } \\
\text { temporada } \\
1964-1965\end{array}$ \\
\hline \multirow{6}{*}{ Amortizaciones } & Mejoras fundiarias 30 años & 150 & 2293 & 53462 \\
\hline & $\begin{array}{l}\text { Maquinarias y herramientas } \\
\text { diez años }\end{array}$ & 165 & 1618 & 24115 \\
\hline & $\begin{array}{l}\text { Animales de trabajo } \\
\text { diez años }\end{array}$ & 24 & 235 & 3508 \\
\hline & Gastos de implantación & & & \\
\hline & 18 años & 597 & 8446 & 139055 \\
\hline & Totales & 936 & 12592 & 220139 \\
\hline
\end{tabular}

Fuente: elaboración propia.

GUADRO 6. ESTIMACIONES DE GAPITAL INICIAL

\begin{tabular}{lrrr}
\hline \multicolumn{1}{c}{ Concepto } & \multicolumn{3}{c}{ Temporadas } \\
& 1938-1939 & $1954-1955$ & $1964-1965$ \\
\hline Insumos y servicios productivos & 4227 & 52517 & 881484 \\
Siete hectáreas sistematizadas para riego & 5600 & 85602 & 1995891 \\
Casa y galpón & 4500 & 68788 & 1603850 \\
Herramientas & 240 & 2353 & 35076 \\
Dos caballos & 1650 & 16177 & 241150 \\
Implantación estimada & 14321 & 202694 & 3337311 \\
Totales & 30538 & 428132 & 8094763 \\
\hline
\end{tabular}

Fuente: elaboración propia.

CUADRO 7. Indexaciones

\begin{tabular}{llcc}
\hline Concepto & $1954-1955$ & $1964-1965$ \\
\hline 1 & Costo de vida & 7.78 & 14.33 \\
2 & Estimación incremento salarios rurales & 14.15 & 16.46 \\
3 & Remuneración media anual de los asalariados & 12.19 & 16.69 \\
4 & Precios agropecuarios & 7.91 & 18.58 \\
5 & Precios no agropecuarios & 9.80 & 14.91 \\
6 & Costo de la construcción & 11.04 & 13.58 \\
7 & Combustibles & 8.69 & 6.97 \\
\hline
\end{tabular}

Nota: para la temporada 1954-1955 en el concepto de estimación de los salarios rurales se utilizó un empalme de serie, desde el año 1939 hasta 1955 se calculó con base en el concepto de remuneración media de los asalariados; a partir de ese año se procedió al uso del índice remuneración real media de los asalariados agropecuarios-índices 1960=100Organización Europea para la Cooperación Económica (1966).

Fuente: elaboración propia. 
Comisión Económica para América Latina y el Caribe [CEPAL] (1991). La cadena de distribución y la competitividad de las exportaciones latinoamericanas: La exportación de manzanas y peras del alto valle del río Negro, Argentina (Núm. LC/G.1683). Santiago de Chile: División de Comercio Internacional e Integración. Recuperado de https://repositorio.cepal.org/handle/11362/29941

Dehais, F. (2000). La manzana y la pera argentina: Su historia. Rio Negro: s. e.

Diamand, M. (1972). La estructura productiva desequilibrada argentina y el tipo de cambio. Desarrollo Económico, 12(45), 25-47. DOI: 10.2307/3465991

García, A. y Rofman, A. (2013). Poder y espacio. Hacia una revisión teórica de la cuestión regional en Argentina. Problemas del Desarrollo, 44(175), 101-124. DoI: 10.1016/S0301-7036(13)719 $04-7$

Instituto Nacional de Estadística y Censos Argentina (1973). Censo nacional de población, familias y viviendas, 1970: Resultados provisionales, localidades con 1000 y más habitantes, todo el país. Buenos Aires: Ministerio de Economía.

Jong, G. (2010). La fruticultura patagónica del Alto Valle: Conflictos de una actividad económica ineficiente en la era del capital tecnológico. Buenos Aires: La Colmena.

Jong, G., Tiscornia, L. y Bandieri, S. (1994). El minifundio en el Alto Valle del Río Negro: Estrategias de adaptación. Neuquén: Universidad Nacional de Comahue.

Kloster, E. (1988). Evolución y situación actual de la fruticultura en el Alto Valle. Boletín Geográfico, $16,37-48$.

Landriscini, G., Preiss, O., Raggi, F., Rama, V. y Rivero, I. (2007). La trama frutícola en el Alto Valle de Río Negro y neuquén: Evolución histórica y situación actual. En M. Delfini, D. Dubbini, M. Lugones, I. Rivero, G. Yoguel y P. Suárez (eds.), Innovación y empleo en tramas productivas de Argentina (pp. 93-144). Buenos Aires: Prometeo Libros/Universidad Nacional de General Sarmiento.

Martínez de Gorla, D. (1994). La colonización del riego en las zonas tributarias de los ríos: Negro, Neuquén, Limay y Colorado. Buenos Aires: Corregidor.

Neffa, J. (1998). Modos de regulación, regímenes de acumulación y sus crisis en Argentina (1880-1996): Una contribución a su estudio desde la teoría de la regulación. Buenos Aires: Eudeba.

Ospital, S. (2012). Políticas públicas para la fruticultura en Argentina, 1930-1943. América Latina en la Historia Económica, 20(1), 78-97. DoI: 10.18232/alhe.v20i1.508

Rapoport, M. (2007). Historia económica, política y social de la Argentina (1880-2003). Buenos Aires: Emecé.

República de Argentina, Consejo Federal de Inversiones (1963). Producto bruto interno. Buenos Aires: Autor. Recuperado de http://biblioteca.cfi.org.ar/documento/producto-bruto-internode-la-provincia-de-rio-negro1953-1960/

Rofman, A. B. (1999). Las economías regionales a fines del siglo Xx: los circuitos del petróleo, el carbón y el azúcar. Buenos Aires: Ariel.

Rögind, W. (1937). Historia del Ferrocarril Sud. Buenos Aires: Establecimiento Gráfico Argentino.

Rossini, M. y Scott, F. (1961). El mercado brasileño para las manzanas argentinas. Informativo de Investigaciones Agrícolas, 172, 9-18.

Rotary Club (1974). Septuagesimo aniversario de la ciudad de Cipolletti: 1903-1973: Homenaje del Rotary Club. Río Negro: Rotary International.

Ruffini, M. (2005). Peronismo, territorios nacionales y ciudadanía política. Algunas reflexiones en torno a la provincialización. Avances del Cesor, 5(5), 132-148. 
Santos, M. (1975). L'espace partagé: Les deux circuits de l'économie urbaine des pays sous-développés. París: Génin Librairies Techniques.

Tagliani, P. (2009). Los inicios del desarrollo económico de Río Negro. Revista Pilquen. Sección Ciencias Sociales, 11(1), 1-13.

US Department of Agriculture (s. f.). Agricultural Statistics Homepage. Recuperado de https://www .nass.usda.gov/Publications/Ag_Statistics

Vapñarsky, C. (1983). Pueblos del norte de la Patagonia: 1779-1957. Rio Negro: La Patagonia.

Vera, J. (2013). Argentina, dos contracciones económicas durante los primeros gobiernos peronistas. $I A D E, 277,149-171$.

Vera, J. (2017). El circuito productivo de la fruta en el Alto Valle del río Negro y Neuquén (1930-1965). El grado de desarrollo desde un enfoque regulacionista (Tesis doctoral). Universidad Nacional de La Matanza, Argentina.

Vera, J. y Ferreyra, M. (2015). Planificación y acción del capital inglés para la gestación y control del circuito frutícola en el Alto Valle de Río Negro. Controversias y concurrencias Latinoamericanas, 7, 179-194.

Wetzler, E. (1941). Algunos aspectos de la fruticultura argentina (Tesis doctoral). Universidad de Buenos Aires, Argentina.

Otras fuentes

Boletín Oficial, República de Argentina [año 1962].

Revista Chacra, años 1955-1966, Editorial Atlántida.

Revista Anales, año 1964. 